\title{
ABSTRACTS Meeting of the European Society for Paediatric Research
}

Heidelberg, Germany, September 11-14, 1972

1. The influence of chronic hemodialysis on uremic osteodystrophy. F. Kuhlencordt, H.-P. Kruse, and W. Baudrtz. I. Medizinische Universitätsklinik, Hamburg, Germany.

In the present study it was important to find out about the influence of a chronic hemodialysis treatment on the histologic bone changes as they present themselves at the beginning of such a treatment. In contrast to an earlier study, where we described the histology of hemodialysis osetopathy in great detail, now some of our patients under chronic hemodialysis (there are $70 \mathrm{pa}$ tients in our program) underwent a re-examination. What was examined was the material from iliac crest biopsies, in which the volumetric density of the spongiosa and the formation and resorption rates were measured by means of microradiography.

Whereas the volumetric density mostly continued to decrease or remained unchanged, the behavior of bone balance in the course of hemodialysis treatment varied considerably. Concerning the bone resorption, an increase as well as a decrease could be observed, obviously depending on the original state of bone turnover at the beginning of the treatment. The reasons for this different behavior of individual cases under practically the same conditions of therapy will probably be heterogeneous and often difficult to prove.

2. Osteodystrophy in children treated by chronic hemodialysis. C. LoIrat. Clinique des Maladies du rein et du métabolisme, Hópital des Enfants-Malades, Paris, France.

This report concerns 18 children dialysed for 1-3 years. Dialysis conditions were equivalent in all cases: calcium dialysate content was $3 \mathrm{mEq} /$ liter. Calcium and vitamin D2 supplements were administered in most cases. Bone disease was determined on radiological examination of the skeleton and by measuring alkaline phosphatase levels. In a first group of 10 patients, no osteodystrophy was present when hemodialysis was started. After 2-3 years of hemodialysis, with a supplementation of vitamin D2 (4,000-10,000 IU/day), one child still has a normal skeleton, four have only moderate osteoporosis, four have slight symptoms of hyperparathyroïdism, and only one has severe osteodystrophy. In a second group of 5 patients, moderate radiological signs of hyperparathyroïdism were present when hemodialysis was started. The average vitamin D2 supplementation was the same as in the first group of patients. After one to two years of hemodialysis, osteodystrophy is unchanged in 3 cases, and in two cases progression has occured. Three children had very severe osteodystrophy when hemodialysis was started. No modification was observed after vitamin D2 treatment (7,000-15,000 IU/day, during 7-8 months). In one case, both signs of rickets and of hyperparathyroïdism regressed after two months of treatment with high doses of 25 hydroxycholecalciferol (16,000 IU/day). But severe hypercalcemia occured, which led to parathyroïdectomy. In the next two cases smallex doses of 25 hydroxycholecalciferol $(2,100-$ $3.700 \mathrm{IU} /$ day during 7.5-8.5 months) allowed good resolution of radiological signs of rickets, without modification of signs of hyperparathyroïdism, which only regressed when parathyroïdectomy was associated with vitamin treatment. Bone biopsies performed in these three cases confirmed the effectiveness of 25 hydroxycholecalciferol: osteoïd and fibrosis decreased, osteoclast variation is less evident. Five parathyroïdectomies were performed: three because of persistent hyperparathyroïdism, one because of severe pruritus, one because of intoxication with 25 hydroxycholecalciferol. In conclusion, it is clear that hemodialysis per se cannot prevent or cure osteodystrophy. Preventive action of vitamin $\mathrm{D} 2$ is uncertain. 25 hydroxycholecalciferol has appeared to be effective in severe renal osteodystrophy. Its preventive role deserves further study.

3. Mineral content of the skeleton in uraemic children. W. SCHUSTER. Paediatric Clinic of the University of Erlangen, Nürnberg, Germany.

With an experimental setup especially designed for paediatrics and based on an isotope method, the mineral content in the bones of the extremities can be determined within an accuracy of $\pm 5 \%$.

The results obtained from 8 uraemic children aged between 6 months and 13 years and treated with vitamin $D$ are reported. Prior to the treatment the mineral content in the metaphyseal area was low, while it was normal or increased in the diaphysis. The data are compared with the morphological findings of the skeleton, and comments are made on the pathogenetic aspects of the corresponding changes in the developing skeleton.

4. Severe renal osteodystrophy (ROD) in small children: treatment with total parathyroidectomy (PTX). R. N. Fine. Childrens Hospital of Los Angeles and University of Southern California School of Medicine, California, USA.

Three boys aged 1.5-3.5 years with hypoplastic kidneys presented with incapacitating $\mathrm{ROD}$ and renal failure $\left(\mathrm{C}_{\mathrm{C}_{\boldsymbol{r}}}<12\right.$ $\left.\mathrm{ml} / \mathrm{min} / 1.73 \mathrm{M}^{2}\right)$. The ROD prevented ambulation in each child. One patient died with pulmonary insufficiency resulting from ROD of the rib cage and pneumonia and two patients underwent total PTX. The response to the latter was remarkable. Radiologic evidence of ROD disappeared within 6 months of surgery and both patients became ambulatory. In addition, both patients grew significantly despite no improvement in renal function. Appetite and affect of both patients also improved dramatically post-PTX. Serum calcium and phosphorus levels were maintained 
within relatively normal limits with the administration of vitamin $\mathrm{D}$, oral calcium supplementation and antacids postoperatively. The latter two patients are presently 15 and 42 months post-PTX and are functioning normally despite continued renal insufficiency.

5. Osteopathy in children with longstanding renal insufficiency. B. KREMPIEN, O. MEHLS, E. RITZ, H. SchüLER, and K. SCHÄrer. Departments of Pathology, Pediatrics and Medicine, University of Heidelberg, Heidelberg, Germany.

Impairment of skeletal growth in children with chronic renal failure is well known as renal rickets. Nevertheless, the problem of whether renal osteopathy in children is a peculiar form of rickets or different from what is seen in the skeleton in nutritional vitamin $\mathrm{D}$ deficiency remains unsolved.

In the following we report on the autopsy findings in the entire skeleton of four children (age 5-9 years) with chronic renal failure showing no rachitic changes at all. The skeleton was studied by histological, histochemical, histomorphometrical, and microradiographical methods in undecalcified microtome and ground sections. The epiphyseal plates of long bones (femur, tibia, fibula, ulna, radius) were not enlarged when compared with normal age matched controls. The hypertrophic cartilage was slightly reduced. There was a nearly complete loss of the primary spongiosa and extreme osteitis fibrosa in the metaphyses with replacement of lamellar bone by atypical woven bone. Bone mass of cancellous bone was irregularly increased showing numerous microcysts with marrow fibrosis. Osteoid volume and cellular activity were clearly increased. The epiphyseal cartilage showed no invasion of vessels and was often occluded towards the metaphysis by a thin bony layer. In cortical bone we found an extreme spongiosation by osteoclastic resorption cavities.

Our findings suggest that uremic bone disease of children (without primary tubular disease) is characterized by osteitis fibrosa and osteomalacia and not by rickets.

6. In Vivo bone calcium mobilization by 25 -hydroxycholecalciferol: role of parathyroid glands, cyclic AMP and kidneys. $P$. Cuisinier-Gleizes, A. Delorme, H. Dulac, and H. Mathieu. Unité de Recherches sur les Maladies du Métabolisme chez l'Enfant (Pr. P. Royer). C.L.E. Château de Longchamp, Bois de Boulogne, Paris, France.

An in vivo bone resorption activity of small doses of 25hydroxycholecalciferol (25-HCC) was established by Blunt et al. (Proc. Nat. Acad. Sci. 61: 1503, 1968). The present experiments were undertaken to study the various factors which would be involved in this action: parathyroid glands, kidneys, cyclic AMP.

Weanling male rats of Sherman strain were given a low Ca, vitamin $\mathrm{D}$-deficient diet during 3 weeks. The rats were operated or sham-operated $1 \mathrm{hr}$ before the injections of the products (25. HCC, dibutyryl cyclic AMP) or their vehicles. The serum calcium was measured $7 \mathrm{hr}$ after the injections. (I) In parathyroidectomized rats the intravenous injection of $2.5 \mu \mathrm{g} 25-\mathrm{HCC}$ does not increase serum calcium $(5.39 \pm 0.109$ vs. $5.36 \pm 0.089 \mathrm{mg} / 100$ $\mathrm{ml}$ ). (2) Nephrectomy which increases, in part by parathyroid hyperactivity, serum calcium levels in vitamin $D$-fed rats $(16.64 \pm$ 0.458 vs. $9.92 \pm 0.136 \mathrm{mg} / 100 \mathrm{ml})$ does not change these levels in vitamin $D$-deficient rats $(6.60 \pm 0.281$ vs. $7.11 \pm 0.112 \mathrm{mg} / 100$ $\mathrm{ml})$. Nephrectomy and 25-HCC injection in vitamin D-deficient rats are also ineffective $(6.38 \pm 0.155 v s .6 .60 \pm 0.281 \mathrm{mg} / 100 \mathrm{ml})$. (3) After parathyroidectomy and $25-\mathrm{HCC}$ injection, the intra- peritoneal administration of DB-AMP (20 mg/100 $\mathrm{g}$ body weight) does not increase serum calcium levels $(5.74 \pm 0.10$ vs. $5.81 \pm$ $0.130 \mathrm{mg} / 100 \mathrm{ml}$ ).

These results show that the bone resorption activity of small doses of 25-HCC, in vivo, requires both parathyroids and kidneys. This suggests that parathyroids would exert a permissive effect either on renal hydroxylation of $25-\mathrm{HCC}$ or on further stage of 1,25-DHCC action. This effect would not be mediated by cyclic AMP.

7. Ultrastructural study of the functional differentiation of parathyroid glands during the embryonal, fetal, and neonatal period. E. Altenähr, J. Wöhler, and K. Franz. Institute of Pathology, University of Hamburg, Hamburg, West Germany.

The parathyroid glands of fetal and neonatal rats as well as of human embryos, fetuses, and newborn infants have been studied electron microscopically. In fetal rat parathyroids the content of organelles involved in synthesis and package of proteohormone increases during the last few days of intrauterine development. The differentiation of rough endoplasmic reticulum, Golgi apparatus, and secretory granules indicates prenatal synthesis of parathyroid hormone, which can be stimulated or suppressed by maternal hypocalcemia or hypercalcemia, respectively. During the first days after birth, there is a considerable increase in activity with a formation of numerous secretory granules in large Golgi fields.

Embryonal human parathyroid gland cells are rich in glycogen. The relative amount of organelle containing cytoplasm increases during intrauterine development. The first electron dense granules, probably already secretory granules can be observed in 6- $-7-\mathrm{cm}$ long embryos weighing $6-10 \mathrm{~g}$, the number of granules increasing subsequently. There appears to be a postnatal increase in gland activity also. Differentiation of cell organelles has reached its highest level in parathyroid glands of mature newborns.

The findings suggest according to clinical speculations that hypocalcemia in premature infants and transitory hypoparathyroidism in newborns is caused by a cellular immaturity of parathyroid glands.

8. Bone osteocytic osteolysis in parathyroidectomized rats by phosphorus deprivation. F. Debove, D. BENEST, P. CursinierGleizes, and H. Mathiev. Unité de Recherches sur les Maladies du Métabolisme chez l'Enfant (Pr. P. Royer) Section de Pathologie Expérimentale C.I.E. Château de Longchamp, Bois de Boulogne, Paris, France.

We previously demonstrated that a low $\mathrm{P}$ diet immediately induces a bone resportion stimulation which is not dependent on the thyroparathyroid glands. The present experiments were designed to study the effects of such a diet on bone morphology.

Parathyroidectomized rats (PTX) and sham-operated rats (PTI) 3 weeks after surgery, were given a low P diet for 3 weeks. The tibiae were studied by microradiography, autoradiography, tetracycline-labeling and cell counting. The serum alkaline phosphatase activity was determined. In all animals there is an enlargement of the epiphyseal cartilage, broad osteoid seams and a decrease in $45 \mathrm{Ca}$ uptake. These abnormalities are more pronounced in PTX rats than in PTI rats. In addition the number of large osteocytes is markedly increased in all animals. In shamoperated rats there is a slight enlargement of the medullar cavity but no increase in the number of osteoclasts. The biochemical 
data confirm the previous ones. In the PTX rats, the alkaline phosphatase activity was increased; it decreased in $\mathbf{P}$ deficiency. In PTI rats, it was increased by $\mathrm{P}$ deficiency. These findings, (I) are consistent with a defect of bone mineralization; (2) suggest that the origin of the osteolysis induced by a low $\mathrm{P}$ diet is primarily osteocytic. Furthermore, the similar increase in the number of large osteocytes in PTI and PTX rats confirms the concept that this osteolysis is not dependent on the presence of the parathyroid glands.

9. Effect of parathyroid hormone on renal reabsorption of bicarbonate. M. VAINSEL. Department of Pediatrics, University of Brussels, Brussels, Belgium.

Renal bicarbonate reabsorption was determined in 26 children following injection of parathyroid hormone. After the injection (200 U USP Para-Thormone, Eli Lilly \& Co), urinary excretion of bicarbonate rose immediately, without any significant change in glomerular filtration rate. At normal plasma bicarbonate levels, the fraction of filtered bicarbonate excreted in the urine was about $20-25 \%$.

Injection of carbonic anhydrase inhibitor (acetazolamide), before or after PTH injection, induced an additional decrease in bicarbonate reabsorption. During infusion of calcium chloride, given after parathyroid hormone injection, the renal reabsorption of bicarbonate reversed to normal values.

These data suggest that parathyroid hormone acts on the proximal tubule by decreasing the reabsorption of bicarbonate. Effects of parathyroid hormone and acetazolamide are additive. Calcium inhibits the renal effects of exogenous parathyroid hormone.

10. Plasma total calcium concentrations in the pregnant rabbit. D. HAREvy and H. J. Shelley. Nuffield Institute for Medical Research, Oxford, England.

A previous report has suggested that, unlike other mammals, the pregnant rabbit has a higher plasma calcium level than that of her fetuses (Economou-Mavrou and McCance, 1958). Blood samples were taken from an ear vein in 18 rabbits before mating and at weekly intervals thereafter. Twelve rabbits became pregnant and were killed at 30 days gestation, blood samples being obtained from their fetuses by decapitation within $3 \mathrm{~min}$ of maternal death. Plasma calcium was determined with the Unicam SP 90 atomic absorption spectrophotometer.

The nonpregnant maternal plasma calcium concentration was $13.88 \pm 0.23 \mathrm{mg} / 100 \mathrm{ml}$ (mean \pm standard error) and did not differ significantly at 7,14 , and 21 days gestation. The concentration dropped to $11.84 \pm 0.39 \mathrm{mg} / 100 \mathrm{ml}$ at 30 days $(p<0.001)$. The plasma calcium in nonpregnant rabbits did not change significantly.

The plasma calcium concentration in 24 fetuses at 30 days was $11.53 \pm 0.12 \mathrm{mg} / 100 \mathrm{ml}$, similar to the maternal value.

11. Metabolism of calcium in the neonate using a stable enriched preparation of ${ }^{46} \mathrm{Ca}$. D. BARLTrop and A. SutTon. Paediatric Unit, St. Mary's Hospital Medical School, London, and the M.R.C. Radiobiological Unit, Harwell, England.

The investigation of the mechanisms underlying neonatal hypocalcaemia has been limited by the lack of a suitable tracer technique. An approach to this problem based on the detection of ${ }^{40} \mathrm{Ca}$ by neutron activation analysis is described. A stable enriched preparation of ${ }^{46} \mathrm{Ca}$ has been added to two experimental milk formulae and the subsequent changes in the concentration of this nuclide in plasma urine and faeces after a single feed have been determined. Data for five premature infants are given and compared with the findings from conventional metabolic balances. Serial determinations of the ratio of ${ }^{40} \mathrm{Ca}$ to total calcium in urine samples allow the turnover of plasma calcium to be measured and provide an index of the absorption of calcium from an individual feed.

12. The influence of $\mathrm{Ca}$ on the STH production in children. S. Nordio, F. MACAgno, and D. TeCilazich. Ospedale Burla Garofalo, Trieste, Italy.

It has been demonstrated by in vitro studies that Ca favors the secretion of a few hormones. Experimental investigations demonstrated that STH stimulates the intestinal absorption of Ca. In children human STH increases calciuria. We studied the effect of a $\mathrm{Ca}$ poor diet and of a $\mathrm{Ca}$ gluconate infusion on the serum STH. A relationship between Ca supply and STH production is emphasized. The relations between vitamin D, PTH and STH are also under investigation.

13. Healing of vitamin D-resistant rickets during immobilization in a case of idiopathic Detoni-Debré-Fanconi syndrome. A. Fanconr. Kinderklinik Kantonsspital, Winterthur, Switzerland.

An 18-year-old girl with idiopathic DeToni Debré-Fanconi syndrome whose severe rickets was being unsuccessfully treated with vitamin $\mathrm{D}$ and potassium phosphate, suddenly fractured her right femur by a very slight fall. An immediate extension of the leg and bed rest for 10 weeks were necessary to treat the fracture. X-rays revealed in addition a number of asymptomatic long bone fractures and looser zones.

During bed rest the medical treatment including 5,000 I.E. 25-OH-cholecalciferol/day was unchanged, except that the daily $\mathrm{Ca}^{++}$-supplement was gradually increased from $500 \mathrm{mg}$ to 3000 mg. Within 3.5 months all the fractures calcified and the rickets healed. The serum alcaline phosphatase activity decreased to nearly normal levels. However, the osteoporosis increased, particularly in the diaphyses of the long bones. The serum $\mathbf{P}$ concentration increased during immobilization from around $2 \mathrm{mg} / 100 \mathrm{ml}$ to values between 3 and $4.5 \mathrm{mg} / 100 \mathrm{ml}$. The previously normal serum $\mathrm{Ca}$ fell within the first days to $8.0 \mathrm{mg} \%$ (ionized $\mathrm{Ca} 3.7$ $\mathrm{mg} / 100 \mathrm{ml}$ ). The serum $\mathrm{Mg}$ decreased from 1.9 to $1.4 \mathrm{mg} / 100 \mathrm{ml}$. On the second day after the fracture, severe tetany occurred and was controlled with intravenous Ca salts. After 3 weeks the serum $\mathrm{Ca}$ reached again the normal range. Parathyroid hormone concentrations were at the upper normal limit (around $40 \mathrm{ng} / \mathrm{ml}$ ). Urinary $\mathrm{Ca}$ excretion decreased from $5-10 \mathrm{mg} / \mathrm{kg} / 24 \mathrm{hr}$ to as low as $0.4 \mathrm{mg} / \mathrm{kg} / 24 \mathrm{hr}$ a week after the fracture.

It is speculated that the horizontal position with partial immobilization changed the Ca-P-homeostasis in a yet unexplained way: it improved the $\mathrm{Ca}$ balance and produced a shift of bone minerals from inactive diaphyseal bone to the metabolically active sites of fractures and rickets.

14. Magnesium and potassium-losing syndrome in a child. $\mathrm{L}$. Paunier, P. C. Sizonenko, A. Vouga, and C. Godard. Clinique Universitaire de Pediatrie, Geneva, Switzerland.

A 8-year-old boy was admitted for tetany and muscular cramps which occurred after a short episode of gastroenteritis and vomiting. Previously, the child had no serious illness and enjoyed good 
general health, but had two episodes of muscular cramps at the age of 4 and 5 years. At physical examination, height and weight were normal for his age (percentile 25). Blood pressure was $110 / 65$ $\mathrm{mm} \mathrm{Hg}$. The following blood values were observed: $\mathrm{Ca}, 84$ $\mathrm{mg} /$ liter; $\mathrm{Mg}, 7.8 \mathrm{mg} /$ liter; $(\mathrm{N}=16-22 \mathrm{mg} /$ liter $) ; \mathrm{Na}, \mathrm{I} 35 \mathrm{meq}$; $\mathrm{K}, 3.9-2.6 \mathrm{meq} /$ liter; $\mathrm{Cl}, 94, \mathrm{pH} 7.63, \mathrm{CO}_{2}, 23.6 \mathrm{~mm} \mathrm{Hg}$. Shortly after the admission, the alcalosis subsided and so did the tetany. Serum $\mathrm{Mg}$ and $\mathrm{K}$ levels remained very low during the subsequent months ( $\mathrm{K}, 2.3-3.2 \mathrm{meq} / \mathrm{liter}, \mathrm{Mg}, 7.5-9.0 \mathrm{mg} / \mathrm{liter}$ ). Hypomagnesemia and hypokaliemia were associated with increased urinary excretion of $\mathrm{Mg}$ and $\mathrm{K}$. No other alteration of renal tubular functions was detected and renal biopsy was histologically normal. With a $\mathrm{Na}$ intake of $3 \mathrm{meq} / \mathrm{kg} \mathrm{bw}$, urinary aldosterone (Aldo) excretion and plasma renin activity (PRA) were normal (Aldo: $5.9 \mu \mathrm{g} / 24 \mathrm{hr}$, PRA: $3.84 \mathrm{ng} / \mathrm{ml} / \mathrm{hr}$ ). With a low $\mathrm{Na}$ diet there was no urinary $\mathrm{Na}$ loss, Aldo and PRA increased normally, $\mathrm{K}$ and $\mathrm{Mg}$ urinary excretions were not significantly different. Spironolactone diminished urinary $\mathrm{K}$ excretion, increased $\mathrm{K}$ plasma levels, but had no significant action on $\mathrm{Mg}$. Triameterene had not such an effect. This observation is probably similar to the two adult cases described by Gitelman et al. (Ann. N.Y. Acad. Sci. 162: 852, 1969) and raises the question of a unique transport defect of $\mathrm{Mg}$ and $\mathrm{K}$ in the renal tubule.

15. Biology of normal brain development. A. N. Davison. University of London, Institute of Neurology, Department of Neurochemistry, London, England.

Development of the nervous system proceeds in a series of interphased stages beginning with embryological events and ending with maturity. Dramatic and well documentated changes follow interference with the formation of nerve cells (e.g. rubella) but it is now realized that later stages of brain development are also susceptible to damage with permanent and untoward sequelae. The early peak establishment of neuroblasts is followed by the maximum rate of glial formation. In the rat these overlap closely so that a homogeneous rate curve for DNA accumulation is seen, but in the human brain two peaks can be discerned in the rate curve. Following neuronal multiplication these is a brain growth spurt due to growth of the cell body, dendritic arborization, synaptogenesis and later myelination. Onset of these various events occurs at different times (in relation to birth) in different species and in different parts of the nervous system, peripheral nerve being one of the first to develop and the neo cortex one of the last. The growth spurt in human brain (when the central nervous system is most vulnerable) extends for a period up to about 2 years after birth; thereafter there is slower increase in dry weight of the brain, myelin gradually accumulating until 15-20 years of age.

Current work is aimed at monitoring such structural changes in biochemical terms. Some examples indicate the value of this approach.

Protein synthesis is a key process in synthesis of cell structure. Control can be influenced by diet and in aminoacidurias by interference with carrier-mediated essential amino acid transport. Entry of ${ }^{75}$ Se-selenomethionine can be monitored in patients. Studies in experimental investigations show the sequence of changes following inhibition of protein synthesis.

Since nerve endings form easily identifiable and separable structures, attempts have been made to quantitate the numbers of synaptic endings in the developing brain. Increased concentration of nerve endings during development can be correlated with changes in ganglioside concentration and with alterations in enzymes responsible for nerve transmitter synthesis. These processes are influenced by thyroxine concentration but possibly not by malnutrition.

Myelination is quantitatively the major structural process in the developing postnatal human brain. During development myelin undergoes well defined changes in its composition, hence analysis of nervous tissue samples for myelin constituents can give a good indication of previous developmental progress. Prior to myelination cholesterol esters accumulate in the brain but soon "early" myelin is formed and finally mature myelin containing basic protein cerebroside predominate. Analysis of these constituents in biopsy or autopsy samples can, therefore, be of value. More sophisticated methods such as isolation of different cell types and separation of characteristic neuronal and glial proteins should be of value in studying cellular changes during the perinatal and first two years of postnatal life so critical to human brain development.

16. Biology of abnormal brain development. N. Herschkowitz. Department of Pediatrics, University of Bern, Bern, Switzer. land.

The development of the brain is regulated by a genetically determined sequence of metabolic events which leads to the successive formation of the neuronal network. Genetic mutations and exogenous factors in each period of brain development can alter the normal sequence and cause functional disturbances which may be irreversible.

The brain develops in four main periods.

1. Period of neuronal proliferation: 15-25 weeks in gestation. Mutations and exogenous factors are known which affect the proliferation rate of neurons leading to malformation of the brain or sensory organs. The proliferated neurons loose after an unknown number of cycles their capability to divide and start to migrate to their determined position. This migratory pattern can be disturbed by mutations, leading to an abnormal histoarchitec. ture. Clinical disorders of motor coordination can be observed later.

2. Period of maximal glial proliferation: 25 weeks in gestation to 1 year. Little is known about disturbances of this phase in development and their effect on brain function.

3. Period of maximal neuronal differentiation: 25 weeks in gestation to 3 years. Abnormal metabolism of compounds which are part of the structure of axons, dendrites and synapses can lead to their abnormal structural formation resulting in disturbed neuronal function. Clinically abnormal psycho-motor development and/or convulsions are frequently connected with these conditions.

4. Period of myelination: birth to approximately 10 years. Abnormal synthesis or degradation of myelin characteristic compounds will affect the structure and function of myelin. Early clinical symptoms are spasticity and ataxia.

The knowledge of the biology of abnormal brain development is useful to plan prevention and treatment of brain dysfunction.

17. Cytokinetics of neonatal cerebral and cerebellar development in rats as studied by the "complete " $\mathrm{H}$-thymidine labeling" method. R. J. HAas, J. Werner, and T. M. Fleidner. Department of Pediatrics and Department of Clinical Physiology, University of Ulm, Ulm, Germany.

The development of cerebrum and cerebellum was studied by 
the complete ${ }^{3} \mathrm{H}$-thymidine $\left({ }^{3} \mathrm{HTdR}\right)$ labelling method of all cell nuclei of newborn rats. This condition can be met by continuous intravenous infusion of ${ }^{3}$.HTdR during the period of gestation. By studying the decrease of labelling index and labeling intensity in the litter for several weeks, evidence for the postnatal turnover of DNA and a possible migration of cells was obtained. The findings showed that in the cerebrum some nerve cells cease to divide before birth, whereas in the superficial brain cell layers a continuation of DNA turnover takes place. It was shown that the cortex is formed by a complicated migration process which is in contrast to the classical concept proposed by Tilney (1933). A continuation of proliferative activity in glial cells could be proved. There is also a high mitotic activity in the subependymal layer of the lateral ventricle up to 10 days after birth. In the cerebellum three different types of proliferative activity in the various cell types could be detected: Purkinje cells; Golgi II cells; cells of nucleus dentatus. These cells cease dividing after birth. Cells of the external and internal granular layer showed a high proliferative activity. A moderate cell turnover rate for basket cells and for cells of the molecular and medullary layers was found. A contribution of granularis externa cells to the interna granular layer by a migratory process is debatable. The findings demonstrate a new approach to the central nervous system in the rat by means of tritiated thymidine labelling. The method of "complete ${ }^{3} \mathrm{H}$ labeling" serves to advance new arguments for or against the existing migration theories. It also is a tool for comparison of neonatal proliferative activities of nerve and glial cells.

18. Gestational age and brain lipids in newborn infants: A chemical study. C. Conde and M. Martinez. Autonomous University of Barcelona, Medical School, Children's Hospital of the "Seguridad Social" Barcelona, Barcelona, Spain.

This paper gives our figures for the major brain lipids in a small group of 40 newborn babies whose gestational ages ranged from 22-44 weeks and who died within the first hours of life. Those children with signs of cerebral damage of any kind were excluded from the study. Our main object was to establish normal values in babies of different gestational ages in order to set the basis for an ulterior study on undernourished infants. The following methods were used: Zamenhof's method for DNA determination and Lieberman's reaction for cholesterol quantification in a digitonide precipitate. Total lipids phosphorus was estimated by Fiske Subarow's technique on the lipid extract. Sphingomyelin and lecithin were separated by chromatography on alumina followed by an alkali hydrolysis and phosphorus determination. The cerebrosides were estimated by their hexose content following Svennerholm's procedure. The fatty acids of total phosphoglycerides, lecithin and cephalin, as well as the F.F.A. were studied by gas chromatography.

Results: DNA, cholesterol, sphingomyelin and cerebrosides showed a definite increase with gestational age. Among the fatty acids, two indices turned out to be useful and statistically significant: $22: 4 w 6 / 22: 5 w 6$ and $w 3 / w 6$, both of them also increasing with age. Plotting our results versus gestational age and with the help of some indices we found a statistically significant correlation between the different data and the gestational age of the babies.

19. The regional distribution of $2^{\prime}, 3^{\prime}$-cyclic nucleotide $3^{\prime}$-phosphohydrolase and cholesterol in the developing human brain. N. R. Belton and J. M. ANderson. Departments of Child Life and Health, and Pathology, University of Edinburgh, and Royal Hospital for Sick Children, Edinburgh, Scotland.

From observations on subcellular fractions of brains of small vertebrates, 2', 3'-cyclic nucleotide 3'-phosphohydrolase (CNP) is regarded as being localized in the myelin sheath or intimately associated structures.

Our studies on human postmortem brain tissue from newborn infants and young children indicate that the activity of CNP is initially very low in all parts of the brain. At varying times in different areas, a rapid increase in CNP activity occurs which correlates well with the increase in cholesterol concentration. These changes occur successively in the medulla, internal capsule, corpus callosum, occipital white matter and frontal white matter, at times which approximate to the onset of myelination as demonstrated histologically. The relative increase in specific activity of CNP is very much greater than that of other enzymes studied including creatine kinase, lactic dehydrogenase and cholinesterase.

It is concluded that an increase in CNP activity is characteristic of myelinating human brain. Preliminary studies show that the enzyme may be useful in the investigation of intrauterine malnutrition.

20. Regulation of brain myelination. J.-M. Matthizu, A. Kohlschürter, and N. Herschkowrtz. Department of Pediatrics, University of Berne, Berne, Switzerland.

Myelination proceeds histologically in two phases: the proliferation of the oligodendrocytes and the transformation of their plasma membranes into mature myelin. The sequence of these developmental events has been investigated in the mouse brain by estimation of the time dependent increments of DNA, proteolipid protein (PLP), basic proteins (BP), and glycolipids (GL). In a first phase, there is a peak increment for DNA and PLP which indicates oligodendroglial proliferation. In a second phase, there is a peak in the increment of BP and GL, indicating formation of mature myelin. These studies have been extended to the Jimpy mutant, a model for human leucodystrophy. Myelin is virtually absent in the CNS of this mouse. The increment of DNA and PLP proceeds at the normal time and at a normal rate; there is, however, almost no increment of BP and GL. The synthesis of one of the GL, sulfatide, in vivo and in vitro, is significantly decreased in the Jimpy brain. Thus we speculate that the myelin maturation phase is missing in Jimpy. These results suggest that proliferation of oligodendrocytes and their differentiation into myelin are under different genetic control.

21. Cerebral arterio-venous differences of acetoacetate and $\mathfrak{n}-\beta$ hydroxybutyrate in children during normo- and hypocapnia. G. Settergren, B. Persson, and G. Dahlquist. Department of Pediatric Anaesthesiology and Department of Pediatrics, Karolinska Institutet, S:t Göran's Hospital, Stockholm, Sweden.

As previously reported children have significant cerebral arterio-venous differences (radial artery-internal jugular vein) of acetoacetate and $D-\beta$-hydroxybutyrate. In the present study the cerebral arterio-venous differences of acetoacetate, D- $\beta$ hydroxybutyrate, glucose, glycerol, FFA, lactate, pyruvate and oxygen were determine during normo- and hypocapnia in children anaesthetized in connection with surgical operations or $\mathrm{X}$ ray procedures. Cerebral flow equivalent values were used to calculate the relative changes in uptake or production of substrates during hypocapnia. The uptake of ketone bodies was 
proportional to the cerebral blood flow and to the arterial concentration. In comparison to reported values in adults the estimated uptake of ketone bodies at a given arterial concentration was about four times higher in children. During hypocapnia, but not during normocapnia, children had a significant lactate production. The vasodilating effect of carbon dioxide on the cerebral blood vessels seems to be the same in children and adults.

22. Studies on the metabolism of 5-hydroxytryptamine in rat's brain during development. K. BoźkowA and J. BOJANEK. National Research Institute for Mother and Child, Warsaw, Poland.

The levels of tryptophan and serotonin and the activities of tryptophan hydroxylase and monoamine oxidase in brain of 1-, 7-, 14-, 28-day-old and adult rats have been estimated. Tryptophan level was estimated quantitatively by the colorimetric method. Serotonin level was measured by two methods, spectrophotometric and biologic, with similar results. Activity of tryptophan hydroxylase has been studied by Freedland's method with our own modification for brain. MAO activity was determined manometrically in the mitochrondrial fraction of rat's brain using tyramine hydrochloride as substrate. The results obtained have shown clear-cut differences in the tryptophan level; the highest tryptophan level was observed in the brain of newborn animals. Serotonin level in a newborn rat's brain is about $50 \%$ of the value found in an adult rat. On the 7 th day of life levels of tryptophan and serotonin are considerably lower in comparison with newborns. During the following days of life the level of tryptophan decreases steadily until maturity, while the level of serotonin increases. The activity of tryptophan hydroxylase was rather high in the brain of newborn rats $(80 \%$ of the value found in adults). It increases rapidly between the first and second week of life with subsequent rise with age. MAO activity in a newborn rat's brain is about $35 \%$ of that of the adult brain. It increases until the 14th day of life.

23. The buffer values and the Bohr effect of human fetal and adult whole blood in vitro. W. Arczynska and L. S. Pron'ном. Service de Pédiatrie, Hôpital Cantonal Universitaire, Lausanne, Switzerland.

The apparent metabolic and respiratory buffer values and the Bohr effect were measured in vitro on human fetal blood and compared to values obtained in the same conditions on adult blood. The apparent respiratory buffer value $\left(\beta^{\prime}=-\Delta \mathrm{HCO}-1 \Delta\right.$ $\mathrm{pH})$ was obtained at constant buffer base by measuring the $\mathrm{pH}$ of saturated blood at different $\mathbf{P}_{\mathrm{Co}_{2}}$. The apparent metabolic buffer value $\left(\lambda=\Delta \mathrm{H}^{+} / \Delta \mathrm{pH}\right)$ was determined at constant $\mathrm{P}_{\mathrm{Co}_{2}}$ by titration of saturated blood with known amounts of base. The determination of the $\Delta \mathrm{pH}$ and of the $\Delta \mathrm{O}_{2}$ content between desaturated and fully oxygenated blood allows to calculate the magnitude of the Bohr effect $\left(-\Delta \mathrm{H}^{+} / \Delta \mathrm{O}_{2}\right)$ by the equation $\Delta \mathrm{H}=\lambda \cdot \Delta \mathrm{pH}$. The results show that the $\beta^{\prime}$ and the $-\Delta \mathrm{H}^{+} /$ $\Delta \mathrm{O}_{2}$ of fetal blood are not significantly different from the adult's values. $\lambda$ increases proportionally to $\mathrm{P}_{\mathrm{CO}_{2}}$ in both fetal and adult blood; at $\mathrm{P}_{\mathrm{CO}_{2}} 40$ and $60 \mathrm{~mm} \mathrm{Hg}$, the values are in the same range for fetal and adult blood. At $\mathrm{P}_{\mathrm{CO}_{2}} 30 \mathrm{~mm} \mathrm{Hg}$ however, the fetal $\lambda$ is significantly lower than the adult's one. The theoretical interpretation of these results is made difficult by the complexity of the whole blood system. Since the in vitro apparent buffer values are on the whole the same in fetal and adult blood, the practical conclusion of this work is that the nomogram of
Siggaard-Andersen can be used for the in vitro acid-base status of fetal blood. This fact is emphasized by the equivalence found between the amount of base added in vitro and the read base excess on the nomogram.

24. Pathogenesis of haemorrhagic pulmonary oedema and massive pulmonary haemorrhage in the newborn. V. A. ColE, I. C. S. Normand, E. O. R. Reynolds, and R. P. A. Rivers. Departments of Paediatrics and Clinical Haematology, University College Hospital Medical School, London, and Department of Child Health, University of Southhampton, Southhampton, London.

Detailed clinical observations were made on 15 infants collapsing with blood-stained liquid flowing out of their tracheas. Coagulation studies were performed on 10 infants, and simultaneous samples of lung effluent and arterial or venous blood were analysed for haematocrit (1l infants), protein concentration (10 infants) and protein composition as determined by gel filtration (7 infants). The results indicated that: $(I)$ the lung effluent was in most cases haemorrhagic oedema fluid and not whole blood; (2) the most important precipitating factor was probably acute left ventricular failure due to asphyxia, although other factors favouring increased filtration of liquid from pulmonary capillaries or causing lung damage may have played a contributory role in pathogenesis; (3) coagulation disorders probably served to exacerbate the condition but not initiate it.

25. Continuous positive airway pressure (CPAP) by nasal cannula in the respiratory distress syndrome (RDS) of the newborn. R. Agostino, M. Orzalesi, S. Nodari, M. Mendrcini, L. Conca, P. G. Savignoni, S. Picece-Bucci, G. Calliumi, and G. Bucci. Institute of Pediatrics, University of Rome, Rome, Italy.

CPAP breathing was administered to newborns with RDS and severe X-ray abnormality by means of a specially built nasal cannula, without tracheal intubation. With this device the fitting is good, leaks are minimized, and pressures as high as 15 $\mathrm{cm} \mathrm{H}_{2} \mathrm{O}$ are easily achieved. The nose piece can be introduced and maintained in situ very easily and permits access to the baby for suction and feeding. From January to June 197220 newborns with birthweight above $1200 \mathrm{~g}$ and severe RDS were observed: 12 were treated only or chiefly by nasal CPAP, $2(16.5 \%)$ died; 2 did not improve with CPAP by nasal or tracheal cannulation, 1 died; 6 were considered as having mild disease and did not receive ventilatory assistance, 2 died; The over-all mortality was $25 \%$ as compared to a previous mortality higher than $50 \%$ in comparable patients. Untoward effects of nasal cannulation included small pressure necrosis of the septum in 2 cases and swelling of the nasal mucosa with partial obstruction in some others: modifications of the technique are under investigation in order to avoid these complications. Pressure of $10 \mathrm{~cm} \mathrm{H}_{2} \mathrm{O}$ was usually required at the peack of the disease in order to decrease the $r-1$ shunt and to allow the administration of $60-75 \%$ inspired O2. Pressure up to $13 \mathrm{~cm} \mathrm{H}_{2} \mathrm{O}$ was seldom required, whereas pressure lower than $10 \mathrm{~cm} \mathrm{H}_{2} \mathrm{O}$ was usually less effective. CPAP usually produced little or no improvement in patients with arterial pH below 7.2, hypercarbia and/or clinically decreased inspiratory effort. Some observations on changes of central venous pressure during CPAP treatment will also be presented.

26. Methods for maintaining alveolar inflation in infants 
mechanically ventilated for very severe hyaline membrane disease. S. Herman and E. O. R. Reynolds. Department of Paediatrics, University College Hospital, London, London, England.

Observations of arterial blood gas tensions and aortic blood pressure were made following random alterations in inspirationexpiration $(\mathrm{I}: \mathrm{E})$ ratio $(1: 2$ and $2: 1)$ and expiratory pressure $(0$, 5 , and $10 \mathrm{~cm} \mathrm{H}_{2} \mathrm{O}$ ) at a mean age of $10 \mathrm{hr}$ on nine infants with very severe hyaline membrane disease (mean birth weight $1580 \mathrm{~g}$, mean gestation 32 weeks) mechanically ventilated with a pressure wave-form approximating to a square wave at a peak airway pressure of $25 \mathrm{~cm} \mathrm{H}_{2} \mathrm{O}$, respiratory frequency of $30 /$ min and mean $\mathrm{F}_{\mathrm{IO}_{2}}$ of 0.95 . The results showed that: (1) the use of a long inspiratory phase and a positive expiratory pressure were synergistic in raising $\mathrm{PaO}_{2}$ and reducing $\mathrm{AaD}_{\mathrm{O}_{2}}$ but the long inspiratory phase was the more effective; (2) the usefulness of a positive expiratory pressure in raising $\mathrm{PaO}_{2}$ was limited by its effect in causing alveolar hypoventilation; (3) no alterations in mean aortic blood pressure were detected.

27. Evoked EEG responses related to perinatal asphyxia: I. study in human newborn infants. A. HrbeK, P. KARLbERG, I. KJellmer, M. Liedholm, and T. Olsson. Department of Pediatrics, University of Göteborg. Research Laboratory of Medical Electronics, Chalmers University of Technology, Göteborg, Sweden.

Reported experiments in adult animals have shown alterations of evoked responses (ER) during acute hypoxia. Late components disappeared first, the primary response was most resistant.

This paper is based on 63 examinations of visual and somatosensory ER in 26 newborn infants with various degree of asphyxia. The changes we found in most of the severe and in a few of the moderate cases were very characteristic but different from those described in adult animals. We observed shape alterations, decrease of amplitude, increase of latency and increased fatiguability. In 12 infants ER were investigated repeatedly afterwards. The abnormality found was graded according to a scoring system.

All infants were given a risk score when discharged from the hospital, based on the perinatal information available (excluding ER scores). Eighteen patients were then seen at regular intervals at the follow-up clinic, where signs of neurological handicaps were especially looked for together with the psychomotor development; they were also tested using the Griffiths mental development scale at 5,10 , and 18 months of age. Ten Children have passed 18 months of age while 8 infants are still below this age. The results demonstrate a close relationship between the abnormality found in ER in the neonatal period and later neurological and developmental aberrations. The perinatal risk score was not as closely related to the outcome of the follow-up studies as were the ER scores.

28. Changes in red cell metabolism and oxygen transport in the newborn infant evoked by thyroid hormones. K. P. RIEGEL, H. Versmold, H. Windthorst, and K. HoRn. Kinderklinik und II. Medizinische Klinik der Universität München, Munich, Germany.

Tissue oxygenation evidently controls red cell 2,3-diphosphoglycerate (2,3-DPG) concentration: 2,3-DPG is elevated in hypoxemic states (e.g. high altitude, congenital cyanotic heart disease, anemia) provided hydrogen ion concentration is normal
(2,3-DPG is lowered in acidemia). After birth normal infants increase red cell 2,3-DPG by approximately 25\% (Delivoria-Papadopoulos et al., 1971; Versmold et al., 1972) despite improved oxygenation conditions. Since the release of birth acidemia can account only in part for this increment, other factors must be involved. Thyroid hormones have been found increased during the first days of life (Malveaux, 1970) and are known to stimulate red cell 2,3-DPG production both in vivo (Miller et al., 1970) and in vitro (Snyder and Reddy, 1970). We therefore studied plasma thyroxine levels and red cell 2,3-DPG in 12 normal newborn infants in short term intervals during the first 2 weeks and calculated a significant correlation between these parameters (2,3-DPG $[\mathrm{mm}]=3.30+0.57 \times$ free $\mathrm{T}_{4}$ Index $[\gamma \%] ; r=0.73$; $n=51$ ). This finding may prove of general physiologic importance, since, 2,3-DPG regulates hemoglobin oxygen affinity (at $3 \% \mathrm{HbF}(n=42)$ : blood $\mathrm{P}_{50}$ [Torr, at pH 7.4, 37 $]=18.86+$ $1.79 \times 2,3-\mathrm{DPG}[\mathrm{mM}] ; r=0.9-$ at $70 \% \mathrm{HbF}(n=29): \mathrm{P}_{50}=$ $18.94+0.55 \times 2,3-\mathrm{DPG} ; r=0.58$; Versmold et al., 1972). It is tempting to speculate that factors governing $\mathrm{O}_{2}$ consumption of tissues also control their oxygen support.

29. Inhibition of DOPA-formation in PKU-patients having a high plasma phenylalanine concentration. H.-CH. CurTius and K. BAERLocher. University Children's Hospital, Zurich, Switzerland.

Phenylketonuric (PKU) patients who have high plasma phenylalanine concentration excrete in their urine subnormal amounts of catecholamine metabolites. In vitro studies have shown that the conversion of tyrosine to L-DOPA by tyrosine 3-hydroxylase, extracted from bovine adrenal glands, is inhibited by high phenylalanine concentrations (Udenfriend, 1967). To determine the in vivo rate of conversion of tyrosine to biogenic amines in PKU patients, we have performed loading tests with deuterated Ltyrosine $(150 \mathrm{mg} / \mathrm{kg})$; tests were done in patients who had high $(25-35 \mathrm{mg} / 100 \mathrm{ml})$, moderately high $(15-20 \mathrm{mg} / 100 \mathrm{ml})$ or low (4 mg/100 ml) plasma phenylalanine concentration as well as in normal controls. The formation of tyrosine metabolites (dopamine, homovanillic acid, vanillylmandelic acid, and 3methoxy-4-hydroxy-phenylglycol) was measured by gas chromatography/mass spectrometry; the deuterium content of these compounds served as an index for the formation of metabolites from the precursor. In patients who had high plasma phenylalanine concentrations $(25-35 \mathrm{mg} / 100 \mathrm{ml})$ only a slight increase of urinary metabolites of biogenic amines was noted. When plasma phenylalanine was between 15 and $20 \mathrm{mg} / 100 \mathrm{ml}$, excretion was more pronounced. When plasma phenylalanine was low, tyrosine loading increased the urinary metabolites to almost the same degree as in normal controls. From these studies it seemed that the in vivo tyrosine 3-hydroxylase activity and thus the formation of L-DOPA and other biogenic amines depended on the phenylalanine concentration in plasma and also in tissues. To confirm this view, L-DOPA ( $50 \mathrm{mg} / \mathrm{kg}$ body weight) was given orally to the same patients when their plasma phenylalanine was high (approx. $30 \mathrm{mg} / 100 \mathrm{ml}$ ). In fact, after a single dose of $\mathrm{L}$ DOPA the same urinary metabolites were excreted at markedly increased concentrations. In vivo inhibition of L-DOPA formation may constitute an important factor in the pathogenesis of neurological symptoms in PKU.

30. Bioelectric phenomena of abnormal brain development. Phenylalanine, thyroid hormone, and EEG power spectra. 
H. G. Lenard and F. J. Schulte. Department of Pediatrics, University of Göttingen, Göttingen, West Germany.

The gradual appearance of 12-14 cps thalamo-cortical rhythms during sleep ("sleep-spindles") between 48 and 52 weeks of gestational age is one of the most constant features in the EEG of the developing human brain. Lack as well as excess of this activity appears to be incompatible with normal brain development. Computer analysis of the EEG power spectra showed an enhanced development of spindle rhythms in infants with untreated PKU. The spectra were significantly abnormal in the 8-16 cps range as early as 5 weeks after term birth. No direct correlation could be established between the power in the spindle range and the blood phenylalanine levels before and after dietary treatment. However, changes in the spectrum were less marked in infants with early introduction of dietary treatment than in children with long lasting hyperphenylalaninemia and severe mental retardation. A striking lack of spindle rhythms was a constant phenomenon in infants and children with untreated primary or secondary hypothyroidism. Power in the spindle range increased under hormonal substitution and fluctuated in relation to the biochemical situation. A normal spindle peak was obtained in those patients only whose further intellectual development was near to normal. The increase in spindle activity in PKU may be due to a depletion of thalamocortical neurons of inhibitory transmitters, e.g. serotonin. In hypothyroidism delayed morphological maturation of thalamocortical synaptic connections appears to account for the lack of spindles; however, the increase of power under hormonal substitution is due not only to a catch-up in the development of synaptic connections but also to functional metabolic influences.

31. Disorders of glycoprotein catabolism. S. Aurro and P.-A. ÖCKerman. Children's Hospital, University of Helsinki, Helsinki, Finland, and the Department of Clinical Chemistry, University Hospital, Lund, Sweden.

At least two diseases are known to be characterized by a defective activity of a glycoprotein degrading enzyme, followed by storage of abnormal metabolites in the cells, namely aspartylglycosaminuria (AGU) and mannosidosis. AGU is based on a defective activity of $N$-aspartyl- $\beta$-glycosaminidase, and mannosidosis is due to an error of $\alpha$-mannosidase. The Finnish series consists of fourty-seven cases with AGU and three cases with mannosidosis. This paper reports clinical, biochemical, and fine structural studies made on the series. Clinical findings in common consist of mental retardation, coarse facial appearance, signs of involvement of connective and osseous system, unusual liability to recurrent infections, impaired speech and small lens opacities. Vacuolized lymphocytes are found in the peripheral blood and bone marrow. Progression of symptoms is evident in AGU but yet uncertain in mannosidosis. Activity of the specific enzyme has been shown to be low though not absent in liver, brain and spleen in AGU, and in liver and white blood cells in mannosidosis. In both diseases, activities of several other lysosomal enzymes are markedly increased. In AG.U, this is most obvious for $N$-acetyl- $\beta$-glucosaminidase, and in mannosidosis, for instance, for $\alpha$-fucosidase. The hugely enlarged lysosomes found in several tissues in AGU and at least in liver in mannosidosis, suggest presence of storage material. In AGU, this material is known to contain an oligosaccharide together with aspartylglycosamine (brain), and in mannosidosis glucosamine and oligosaccharide residues rich in mannose. The excretion of aspartylglycosamine in AGU-patients is continuous and does not occur in healthy family members. The cases with mannosidosis excrete oligosaccharide fractions rich in mannose. The inheritance pattern of AGU is autosomal recessive, but is not known yet in mannosidosis.

32. Genetically determined leakage of lysosomal enzymes: a possible pathogenetic mechanism leading to an atypical mucopolysaccharidosis (I-cell disease). U. WresmanN, F. Vassella, and N. Herschkowirz. Department of Pediatrics, University of Bern, Bern, Switzerland.

Multiple lysosomal enzyme deficiency has been found in cultured fibroblasts of four patients with I-cell disease. In all four cell lines decreased degradation of 35-S-MPS and of 35-Ssulfatide could be demonstrated. In a patient which was available for clinical studies abnormal morphology of lysosomes with storage of various material in the cells of liver and peripheral nerve was observed by electron microscopy. The finding suggested a faulty degradation of lysosomal substrates due to enzyme deficiency as was observed in cultured fibroblasts. In the conditionned media, in which the fibroblasts of the four patients had been growing for 3 days increased lysosomal enzyme activities were measured. Increased cell destruction or reduced inactivation of lysosomal enzymes in the culture medium could be excluded to be the cause of high enzyme activities. Therefore leakage of enzymes from apparently undamaged cells has to be considered. In order to confirm this finding in vivo lysosomal enzymes were measured in plasma, urine, and CSF of the patient. Up to 100 times normal enzyme activities were found in these extracellular fluids. $\mathrm{PH}$ optimum and heat inactivation of these enzymes was normal. No rise in the activity of nonlysosomal enzymes was found. The increased enzyme levels could not be corrected by drugs, such as cortison and Vit $\mathbf{E}$ given to the patient. Loss of lysosomal enzymes could lead to intracellular depletion of enzymes in the cells of the patient and thus cause the metabolic abnormalities observed. However the pathological changes in the connective tissue could also be the consequence of the presence of high activities of lysosomal enzymes in the extracellular fluids. At present none of these alternatives can be proven conclusively.

33. Citrullinaemia and brain damage. A. OKken, J. F. van Der Bly, and F. A. Hommes. Department of Pediatrics, University of Groningen, School of Medicine, Groningen, The Netherlands.

Citrullinaemia, a rare inborn error of the urea cycle, occurs in at least two forms. The mild cases can be treated by low protein diets, the severe form ends rapidly with a fatal outcome (Van der Zee et al., 197I). A second case of this variant of citrullinaemia has recently come to our attention. The patient developed signs of brain damage after $60 \mathrm{hr}$ of apparently normal life. Increased concentrations of blood ammonia could never be demonstrated, but blood citrulline increased to $2.6 \mathrm{~mm}$. A liver biopsy demonstrated the virtual absence of argininosuccinate synthetase. The activities of carbamylphosphate synthetase and ornithine transcarbamylase were higher than those of controls, while the activity of arginase was lower. Adaptation of the activities of urea cycle enzymes can therefore occur in man.

Postmortem examination of the brain of the patient revealed massif destruction of brain tissue. As the ammonia concentration per se cannot be responsible for the brain damage, citrulline 
itself may be toxic for a very basic metabolic pathway in brain. It was found that in slices of the adult rat brain aerobic glucose utilization was inhibited $30 \%$ by $5 \mathrm{~mm}$ citrulline. As slices of brain do not show a constant rate of glycolysis, perfusion of rat brain in situ was carried out. This system showed a constant rate of glycolysis, as measured by glucose uptake and lactate production. Addition of $5 \mathrm{~mm}$ citrulline to the perfusion medium, inhibited glycolysis $25 \%$. This system demonstrates that concentrations of citrulline which are observed in the acute form of citrullinaemia can be toxic to a very basic metabolic process in brain.

34. Evidence of altered cerebral serotonin metabolism in Down's syndrome from measurements of cerebrospinal fluid acids. S. P. Fällström, M. Liedholm, and P. Lundborg. Departments of Paediatrics and Pharmacology, University of Göteborg, Göteborg, Sweden.

Various authors have reported low levels of blood serotonin in Down's syndrome. It has also been suggested that a cerebral serotonin abnormality might be responsible for the muscular hypotonia, mental retardation and other cerebral symptoms of mongolism. This assumtion has initiated therapeutic trials with 5-hydroxytryptophan (5-HTP), a serotonin precursor. However, till now a disturbed cerebral serotonin metabolism has not been demonstrated.

The major degradation product of serotonin is 5-hydroxyindole acetic acid (5-HIAA). The levels of 5-HIAA in the cerebrospinal fluid (CSF) of mongoloid children have been compared with the levels in nonmongoloid children. During the first half year of life no difference was found, but after that age the mongoloid children had significantly lower levels $(P<0.001)$. The results indicate a defect cerebral serotonin metabolism in Down's syndrome.

Treatment from birth with 5-HTP prevented the decrease in CSF 5-HIAA levels. In most infants the muscular hypotonia decreased. The psychomotor development of the treated group is followed and compared with that of untreated mongoloid children. A number of the treated children have now reached the age of 18 months, and so far the comparison does not seem to reveal any pronounced difference in the mental development of the two groups.

35. Familary degenerative disorder of the cerebrum with ultramicroscopic changes of the nucleoli of the nervous cells. W. Schlote, H. J. Bremer, D. LeUpold, and H.-U. Benz. Department of Ultramicroscopic Pathology, University of Tübingen, Tübingen, and Department of Metabolic Diseases and Nutrition, Center of Internal Medicine and Paediatrics, University of Ulm, Ulm, West Germany.

A progressive cerebral disorder with unusual-and to our knowledge-undescribed ultramicroscopic changes have been observed in four children of a family. Clinically, the symptoms started between the fifth week and the sixth month after birth with seizures. One child died in a status epilepticus when 6 years old, the other children are alive $(13,11$, and 2 years old, respectively). The symptoms are idiocy, hypotonia of the muscles with rigor and pyramidal signs, ataxia, and constant EEG changes.

A cerebral biopsy of the eldest child shows signs of degeneration and loss of nervous cells. Ultramicroscopically, degenerated nervous cells lack a nucleolus. The nucleus contains material which consists probably of segregated parts of the nucleolus.
Besides other changes there was also an enormous increase in the number and size of synaptic vesicles.

The details of ultrastructural, biochemical, and clinical findings are presented.

36. Isolation of measles virus from measles encephalitis. V. TER Meulen, Y. Käckell, D. Müller, M. Katz, and R. MeyerMANN. Department of Virology, University. of Würzburg; Department of Pediatrics and Neuropathology, University of Göttingen; Göttingen, West Germany, and Department of Tropical Medicine, Columbia University, New York, New York, USA.

The etiology and pathogenesis of measles encephalitis, as a complication of acute measles infection, is still unknown. The hypothesis, that this encephalitis is caused by the direct action of measles virus in brain tissue or is only the result of an antigen antibody reaction, has never been proven. All attempts to isolate the infectious agent from brain material or to demonstrate an autoimmune mechanism has been unsuccessful. A 40-year-old male patient with the typical symptoms of measles encephalitis was admitted to the department of anaesthesiology, University of Göttingen, with a respiratory distress syndrome and artificial respiration was necessary. $\mathrm{He}$ died 7 weeks later being constantly on the respirator. The neuropathological examination of the brain tissue confirmed the clinical diagnosis. Immunofluorescent studies of brain sections with hyperimmune serum against measles revealed the presence of measles antigen in ganglion and glia cells. Infectious virus could not be isolated from brain homogenates. However, brain tissue, trypsinized and cocultivated with susceptible cell lines for meales virus, resulted, after several passages, in a cytopathic effect and in the recovery of infectious measles virus. The isolated virus did not differ antigenically from measles virus. Other biological or physicochemical properties have not yet been tested. The isolation of measles virus from this case demonstrates that an active measles virus replication in the central nervous system plays a role in the etiology of measles encephalitis.

37. Influence of phototherapy on unconjugated bilirubin in bile of newborn infants with hyperbilirubinemia. A preliminary study. H. T. LUND and J. JACOBSEN. Department of Pediatrics, chester, Manchester, England, and the Faculte de Medicine, Biochemistry, University of Aarhus, Aarhus, Denmark.

The concentration of unconjugated bilirubin was measured in duodenal bile in 12 newborn infants with hyperbilirubinemia without signs of isoimmunization. Seven infants received phototherapy for 24 hours between bile samples, while five infants had no treatment and served as controls. During phototherapy the colour of the bile changed from a pure yellow to a brownish black colour, and the concentration of unconjugated bilirubin was on the average doubled. In the control patients no essential change in the colour or concentration of unconjugated bilirubin occurred. The result is statistically significant $(P=0.05)$. How phototherapy directly or indirectly affects the excretory mechanism of bilirubin is obscure. The findings are discussed in relation to similar studies performed in Gunn rats with bile fistula.

38. The influence of donor blood temperature on hormonal and metabolic changes during exchange transfusion. M. FeKeTE, R. D. G. MiLner, J. S. Hodge, and R. Assan. Departments of Child Health and Chemical Pathology, University of Man- 
Chester, Manchester, England, and the Faculté de Medicine, Paris, France.

The purpose of the investigations was to study the effect of donor blood temperature on the hormonal and metabolic responses of the infant. Measurements of plasma glucose, free fatty acid, glycerol, insulin, growth hormone and glucagon were made during exchange transfusions performed with blood heated to $36.5-38.5^{\circ}$ or cooled to $10-13^{\circ}$. Term, normally grown infants suffering from rhesus incompatibility were studied. Ten received warm transfusions and nine, cold transfusions. Birth weight, gestational and postnatal age, the rate and volume of transfusion were similar in the two groups. Cold transfusions caused a progressive fall in rectal, umbilical vein and skin temperature, whereas warm transfusions caused no significant change in body temperature. Infants receiving cold transfusions had a greater net positive balance of glucose and a smaller net negative balance of free fatty acids than those receiving warm transfusions. Other metabolic and hormonal responses to exchange transfusion were similar in the two groups. It was concluded that while exchange transfusion performed with cold blood did cause thermal stress to the infant, the metabolic consequences were slight and mitigated by the glucose in the donor blood. No evidence was obtained to indicate that insulin, growth hormone, or glucagon played a part in the response of newborn infant to cold.

39. Importance of some genetic factors in neonatal jaundice of white and Negro infants. M. Orzalesi, P. Lucareilli, R. Scarabino, F. Gloria, R. Palmarino, and E. Bottini. Departments of Genetics (School of Science) and Pediatrics (School of Medicine), University of Rome, Rome, Italy, and Department of Pediatrics, Yale University School of Medicine, New Haven, Connecticut, USA.

We have previously shown that in newborn infants incompatible with their mothers in the $\mathrm{ABO}$ system the incidence of signs of isoimmunization was dependent upon the phenotype of placental alkaline phosphatase (Pl). In $\mathrm{B}$ incompatible infants the lowest incidence of jaundice and/or direct Coombs test positivity was observed in subjects carrying $\mathrm{Pl}^{\mathrm{fl}}$ allele of placental alkaline phosphatase. The present study concerns the role played by $\mathrm{Pl}$ and other factors in neonatal jaundice and in the differences observed between two groups: white and Negro. The study includes 460 infants (362 white and 98 Negro) incompatible with their mothers in the $\mathrm{ABO}$ system. The following parameters were recorded: sex, birth weight, $\mathrm{ABO}$ phenotype, $\mathrm{PI}$ phenotype, phosphoglucomutase locus $1\left(\mathrm{PGM}_{1}\right)$ phenotype and the presence of jaundice during the first 4 days of life. The over-all incidence of jaundice was significantly higher in Negro infants (34\% vs. $24 \%$; $P<0.05$ ): this was true even when considering only infants with a birth weight $>2500 \mathrm{~g}$. Separate analysis of infants with $A$ and $B$ group revealed that this difference was present and highly significant $(P<0.01)$ only in subjects with $B$ group. In both white and Negro infants of $B$ group there was a negative association between jaundice and $\mathrm{Pl}^{\mathbf{f}_{1}}$ factor. In Negro infants jaundice was also positively associated with $\mathrm{PGM}_{1}{ }^{1}$ factor. Since $\mathrm{I}^{\mathrm{B}}$ and $\mathrm{PGM}_{1}{ }^{1}$ alleles are more frequent in Negro infants, while $\mathrm{PI}^{{ }^{1}} \mathrm{I}$ is more frequent in white infants, the higher incidence of neonatal jaundice in Negro infants could be partially related to these differences in the genetic background.

40. Plasma concentrations of amylobarbitone in mothers and their newborn infants. B. KraUer, H. Draffan, F. Williams,
R. Clare, C. T. Dollery, and J. W. Scopes. Royal Postgraduate Medical School and Institute of Child Health, Hammersmith Hospital, London, England.

It is well known that newborn animals and humans may be more sensitive to drugs than adults. While a limited ability to metabolise drugs has been established in the young of several animal species only scanty information is available for the human newborn. A restricted capacity of drug metabolism may be reflected by a prolonged half life in vivo for drugs that depend on metabolic transformation for their elimination. Since barbiturates are often used in pregnancy and labour and are cleared principally by metabolism, a study of the plasma concentrations of amylobarbitone and its major metabolite hydroxyamylobarbitone was undertaken in mothers and their newborn infants when a single dose of this drug had been given to the women during labor. The drug and its metabolite were measured by gas chromatography-mass spectrometry. Similar drug concentrations were found in cord and maternal plasma at delivery, indicating the unrestricted placental passage of the drug. From the declining amylobarbitone concentrations first order kinetics were demonstrated in all cases. The plasma half-life was twice as long in the newborns as in the mothers. The plasma concentrations of the major metabolite increased during 12-24 $\mathrm{hr}$ after delivery in both mothers and newborn infants and decreased thereafter.

41. Pharmacokinetic and metabolism of sulfamethoxazol in infants and children. M. Vest, A. Olafsson, U. LetB, and C. HäNGGr. University Children's Hospital, Basel, Switzerland.

Infants and children, who were treated with sulfamethoxazol for various infections, mostly of the urinary tract, obtained the first dose as i.v. injection. The amount given was $580 \mathrm{mg} / \mathrm{m}^{2}$ surface area. Blood samples were drawn after $1,2,4,8$, and 24 hours and urine was collected for three 4 -hr and one 12-hr period. Unchanged sulfonamide together with ${ }^{4} \mathrm{~N}$ acetylated sulfonamide and glucuronide were estimated separately. From the values obtained the plasma disappearance rate of free and conjugated sulfonamide as well as the volume of distribution was calculated. In the urine the amount and percentage of the various conjugates were estimated. The results obtained show marked differences in the rate of excretion and of conjugation of the various compounds with age.

42. Polyunsaturated fatty acids in plasma lipids of cord blood. B. Wharton and A. Fosbrooke. Institute of Child Health, London, England.

The fatty acid composition of plasma cholesterol ester and triglyceride has been determined in the cord blood of 19 term, 16 preterm, and 14 light-for-date babies.

Compared with the values in term babies the proportion of polyunsaturated fatty acids were significantly lower in the preterm group.

Results (mean in $\mathrm{g} / 100 \mathrm{~g} \pm$ one $S D$ )

Cholesterol ester: Linoleic acid in term babies $17 \pm 4 \%$, preterm $13 \pm 3 \%, P<0.001$; arachidonic acid in term babies $11 \pm$ $3 \%$, preterm babies $8 \pm 2 \%, P<0.001$.

Triglyceride: linoleic acid in term babies $11 \pm 2 \%$, preterm babies $7 \pm 3 \%, p<0.001$.

In the light-for-date babies the values were similar to those in the term group.

The high proportion of arachidonic acid in cord plasma lipids of term babies has been observed previously but its physiological 
significance is uncertain. This study shows that the proportion is affected by the period of gestation.

43. Small for dates neonates: evidence of defective gluconeogenesis from aminoacids. C. Dacou-Voutetakis, D. AnAGnostakis, D. Nicolopoulos, and N. MATSANIotis. Athens University, Department of Pediatrics, "St. Sophie's" Children's Hos. pital, Goudi, Athens, Greece.

Intrauterine growth retardation is frequently encountered in newborns with transient neonatal hypoglycemia. To test the hypothesis that intrauterine malnutrition may prevent the normal development of enzymes involved in gluconeogenesis, glucose formation from aminoacids was examined in 22 small-for-date (SFD), 6 preterm (PT), and 10 full term (FT) neonates. L-Arginine $(2.38 \mathrm{~mm} / \mathrm{kg})$ or saline was given orally and blood glucose $(B G)$ was determined in capillary samples at $-30,0,+30,60,90$ and $120 \mathrm{~min}$. BG increments following the administration of arginine in FT, PT, and SFD neonates were 21.4 $\pm 5.8,13.5 \pm 1.3$, and $9.8 \pm 8.1$ (mean $\pm \mathrm{sD}$ ) $\mathrm{mg} / 100 \mathrm{ml}$, respectively. The corresponding increment after saline administration was $3.7 \pm 1.4 \mathrm{mg} \%$. The difference in the hyperglycemic response to the aminoacid was significant between FT and SFD $(P<0.001)$, and between PT and SFD $(P<0.02)$ neonates. Saline did not result in a significant rise in BG concentration. In $72.7 \%$ (16 out of 22) of SFD neonates arginine produced a $B G$ rise which was smaller than the mean value minus 2 sD of the FT group and similar to that caused by saline. In the remaining $27.3 \%$ the response was similar to that in FT babies. These data are interpreted as probably reflecting impaired gluconeogenesis from aminoacids in the "dystrophic" neonate, although other mechanisms cannot be excluded. The heterogeneity observed in SFD neonates is not surprising since the pathogenesis of intrauterine growth failure is not uniform.

44. Protein intake and plasma osmolality in low birth weight infants. D. P. Davres. Welsh National School of Medicine, Department of Child Health, Cardiff, Wales.

The optimum protein intake for the low birth weight in early postnatal life is not solved. The rapid growth during this period requires a relatively high dietary protein intake, but there are potential hazards of this. The danger of an elevated level of plasma amino acids, particularly tyrosine and phenylalanine, on the developing brain is well documented, but less attention has been paid to the existence of potentially harmful hyperosmolar states which may accompany a high protein intake. This increased solute load imposes a considerable stress on the immature kidney which can excrete urine of only limited osmolality.

The purpose of this study communication is to record the plasma osmolality of low birth weight infants who have been randomly assigned to one of three milk formulas of varying pro. tein content. The infants were maintained on these formulas for a total period of two months.

The biochemical data will be presented and the significance of the results discussed.

45. Current considerations in the antenatal detection of human genetic disorders. M. M. KABACK. University of California, Los Angeles Harbor General Hospital, Torrance, California, $U S A$.

Transabdominal amniocentesis in the early second trimester of pregnancy is rapidly evolving as an innovative and important tool in modern genetic counseling. Accessibility to somatic cells of fetal origin from amniotic fluid samples and the development of methods for the efficient in vitro cultivation of such cells provides the mechanism for detailed cytogenetic and metabolic evaluation of the human fetus prior to 20 weeks gestation. Coupled with changing social and legal attitudes toward abortion in many areas, programs for intrauterine diagnosis and selective abortion are rapidly emerging. Families at significant risk for severe and untreatable cytogenetic or inborn metabolic errors in their offspring, who might otherwise be fearful of conceiving or completing any pregnancy, may now choose to monitor their pregnancies and thereby be assured of having only children unaffected by the disorder in question (assuming the couple would elect to terminate a pregnancy where an affected fetus is identified).

Over the past 4-5 years in North America, approximately 1500 pregnancies have been monitored during the second trimester because of substantial risk of detectable genetic disease in the fetus. Amniocentesis was performed in $75 \%$ of these pregnancies because of risk for chromosomal abnormality in the fetus (advanced maternal age, previous chromosomal aberration in a sib, parental balanced translocation). Of these cases, $7 \%$ were monitored for X-linked recessive disorders (Lesch-Nyhan syndrome, Duchenne dystrophy, etc.). High risk for a severe autosomal recessive disorder (Tay-Sachs disease, Type II glycogen storage disease, etc.) accounted for $13 \%$ of this group, and the small number of remaining cases were studied for other miscellaneous reasons. Over-all, $7 \%$ of these pregnancies were electively terminated as the result of positive diagnoses in cultured amniotic cells.

Significant questions concerning the efficacy and safety of these procedures still remain unanswered. The recorded incidence of "significant complications" is approximately $2 \%$, but an exact definition of the total risks for this procedure to mother or fetus cannot be given as yet. Prospective programs are underway attempting to deal with this most critical issue.

If intrauterine diagnosis and selective abortion is to become an important tool in the widespread "control" of severe genetic disease, it would be most effective in this regard if the high risk couple could be identified prior to the birth of the index case. Genetic screening programs amongst couples of child-bearing age might be implemented to delineate families at risk before the birth of an affected child. Intrauterine monitoring of each pregnancy in only these couples should enable these families to reproduce without fear and could conceivably eliminate the disease state from the tested population. Such a pilot program has been initiated using Tay-Sachs disease heterozygote detection as the prototype.

Important social and ethical questions are raised by these considerations. Intrauterine diagnosis and selective abortion of fetuses with serious genetic disease might be considered as only an interim approach; one which provides for certain individual families, a humane, albeit imperfect, alternative. Unquestionably, continued research leading to effective treatment or even "cure" of such conditions should remain the ultimate goal.

46. The technique and risks of amniocentesis in early pregnancy.

H. E. ReIss. Hackney Hospital, London, England.

Amniocentesis yields both liquor and foetal cells. The liquor can be used for certain biochemical studies. The cells are used for immediate screening to determine foetal sex and for tissue 
culture to study the foetal karyotype and certain specific biochemical abnormalities. Determination of foetal karyotype may reveal a variety of chromosomal abnormalities, but for the antenatal diagnosis of metabolic disorders specific tests are required for any one clinical condition and the technique therefore does not permit a wider type of screening program. The timing of amniocentesis in pregnancy, the route chosen for the tap, and the technique used will be discussed in detail. Reference is made to the volume of amniotic liquor in relation to the amount of fluid withdrawn. Possible hazards of amiocentesis are infection, abortion, Rhesus sensitization, trauma to mother or foetus, and remote foetal damage. The problem of placental localization in early pregnancy will be discussed. The results of a personal series will be presented with reference to the results obtained and the problems encountered.

47. Prenatal diagnosis-prospects, administration and ethics. C. O. CARTER. MRC Clinical Genetics Unit, Institute of Child Health, London, England.

The total load of anomalies in children which may in time be preventable by prenatal diagnosis is about 40 per thousand total births. This is made up of about 5 per thousand chromosomal anomalies, 10 per thousand due to mutant genes of large effect (including recessive inborn errors of metabolism and usually dominant structural anomalies) and 25 multifactorially determined.

The present possibilities include the prenatal detection of all major chromosomal abnormalities and about a third of the inborn errors of metabolism. Only a few of the multifactorially determined major congenital malformations are detectable, for example, anencephaly by ultrasound at 18 weeks.

Future prospects include the detection of: structurally minor, but perhaps clinically important, chromosomal changes by the new banding techniques; further conditions due to mutant genes by the discovery of methods of obtaining foetal blood, of methods of inducing the activity of genes that are normally silent in amniotic cells, and of close linkages to genetic markers; externally recognisable congenital malformations by foetoscopy.

The best administrative arrangements are still uncertain. In the U.K. it is felt that investigation for chromosomal anomalies is best done at Regional or University Medical Centres, but that investigations for specific inborn errors of metabolism are more specialised and at present best done at the one or two laboratories which have a research interest in that enzyme.

The ethical issues are not difficult in practice provided that the principle is accepted that decisions, on whether to ask for prenatal diagnosis and what action to take if a serious anomaly is found, rest with the parental couple. The doctor's role is to provide full information on diagnosis, prognosis and risks and then to carry out the parents' wishes, where these are not repugnant to his own beliefs.

48. Techniques for rapid prenatal diagnosis of some inborn errors of metabolism. H. GaljaARD. Department of Cell Biology and Genetics, Medical Faculty, Rotterdam, The Netherlands.

The possibility of prenatal diagnosis using cultured amniotic fluid cells has been described for more than 20 inborn errors of metabolism. Yet, the number of cases reported is limited and the periods required for analysis after amniocentesis (16th-20th week of pregnancy) have been rather long (4-10 weeks). The large number of cells required for conventional biochemical assays $\left(10^{5}-10^{-7}\right.$ cells) and the unpredictable growth speed of cultured amniotic fluid cells are two major problems. The present communication deals with methods which in principle enable a considerable reduction in the number of cells required for prenatal diagnosis. The sensitivity of the biochemical assay can be increased by reducing the incubation and measuring volumes. Model experiments were carried out by incubating diluted cell homogenates of cultured amniotic fluid cells and fibroblasts in reduced volumes (down to $0.2-5 \mu \mathrm{l}$ ) of substrate under paraffin oil to prevent evaporation and under direct microscopic control. Estimation of fluorescence or extinction values are carried out respectively after dilution to $500-\mu 1$ or in $25-\mu 1$ microcuvette: The possibilities of measuring extinction values in smaller volumes using microcapillaries and a microspectrophotometer design will be discussed. Results on the scaling down of enzyme determinations are given for arylsulfatase (metachromatic leucodystrophy), $\alpha$-1-4-glucosidase (glycogenosis II), $\alpha$-galactosidase (Fabry's disease), and $\beta$-D-acetylglucosaminidase and $\beta$-galactosidase (GM1 and GM2 gangliosidosis). Furthermore a sampling procedure was attempted enabling the expression of enzyme activity per cell. After sufficient cell growth on plastic foil quick freezing $\left(-70^{\circ}\right)$ and freeze-drying in vacuo at low temperature is performed. Subsequently pieces of foil containing a counted number of lyophillized cells are dissected under the microscope which are immediately incubated into minimal volumes of substrate. By using this procedure cell loss is minimal and parallel protein determinations are being avoided. Results on the application of this procedure are presented for cultivated cells from controls, heterozygotes and patients with glycogenosis II and TaySachs disease.

49. The new techniques for chromosome identification in prenatal diagnosis. E. M. Bühler, H. Müller, M. OszTovics, and G. R. STALDER. Universitäts-Kinderklinik Basel, Genetisches Institut, Basel, Switzerland.

Two examples of families are presented in whom translocations of small chromosome segments were not detected in the unbalanced state by conventional methods of chromosome identification. By means of the two new methods (1) fluorescence after differential staining with Quinacrine and (2) Giemsa staining after denaturation and renaturation, however, these translocations could not only be detected but also designed to specific chromosomes.

In one family two children with symptoms of trisomy 13 were found to have 46 chromosomes, the short arms of a C-chromosome being barely recognizably enlarged. The additional piece of chromosome showed the banding pattern of the distal portion of the long arms of chromosome 13. The father was shown to have a balanced 13q-; $9 p+$ translocation. The only child of another family who presented with an unspecific malformation syndrome had an apparently normal karyotype as shown with the conventional methods. By means of the new methods chromosome 9 was found to carry a small translocation which could be shown to be derived from a chromosome 2 in the balanced $2 q-; 9 p+$ karyotype of the father.

In prenatal diagnosis where the decision whether pregnancy should be interrupted or not depends on the unequivocal recognizability of balanced and unbalanced chromosome translocations these new methods of chromosome identification seem to become increasingly important. 
50. Amniotic cell cultures: report of results obtained in 50 amniocenteses. E. Vamos-Hurwitz, P. Petit, L. Thiry, and H. LoEb. Department of Pediatrics and Laboratory of Pathology and Election Microscopy, University of Brussels, School of Medicine, Institut Pasteur du Brabant, Brussels, Belgium.

Fifty cultures were initiated from amniotic cells obtained through transabdominal amniocenteses performed at gestational ages ranging from 8 to 30 weeks, for various indications including 18 antenatal diagnoses of inborn disorders. Cell growth was observed in 37 instances. Although tissue culture conditions did not appear of particular relevance, it was found that the number of viable cells initially inoculated was the prime factor involved in obtaining adequate cell growth. Among the successful cultures, 14 karyotypes could be made. In a case with a family history of galactosemia, this diagnosis could be excluded through the use of selective medium for galactosemic cells. In nine samples taken in cases of maternal rubella, attempts to demonstrate the presence of the virus were performed. Successful recovery was recorded in two instances in cultured amniotic cells, whereas all uncultured samples were negative. In view of these findings, some prospects concerning the study of transplacental infections are evoked.

51. A direct quantitative TLC-system for pre- and postnatal assay of lipid abnormalities. J. Clausen, J. C. Melchror, and H. Verder. Neurochemical Institute, Copenhagen, and University Clinic of Paediatrics, Copenhagen County Hospital Gentofte, Denmark.

A quantitative thin layer chromatographic method involving separation of polar lipids of biological fluids or from cells on Kiesel gel $\mathrm{H}$ by chloroform-methanol-25\% $\mathrm{NH}_{3}$ (10:30:5), followed by spraying with ammonium molybdate reagent, gave rise to a quantitative development of molybdenium Blue corresponding to every lipid fraction. This method made it possible to assay quantitatively, the individual polar fractions by subsequent photometric scanning. Results could be obtained within two to four hours. The results of pre- and postnatal diagnosis will be demonstrated and related to data obtained by enzymic assays for enzymic disorders.

52. Simulation of genetic mucopolysaccharidoses in normal human fibroblasts by alteration of medium pH. S. O. LIE, V. A. McKusrck, and E. F. Neufeld. Division of Medical Genetics, Johns Hopkins Hospital, and National Institute of Arthritis and Metabolic Diseases, NIH, Bethesda, Maryland, USA.

Recent reports have emphasized the importance of $\mathrm{pH}$ control in cell culture systems. Growth rate, contact inhibition of growth, and cell mobility are all strongly influenced by $\mathrm{pH}$ of the culture medium. No biochemical explanation of these phenomena has been offered so far. We have found that small increases in the $\mathrm{pH}$ of the culture medium strongly influence the metabolism of sulfated mucopolysaccharides by normal human fibroblasts in culture. Catabolism of these molecules is progressively inhibited as the $\mathrm{pH}$ of the growth medium is raised from 6.8 to 8.0 . The final cell density increases with the same changes. The capacity to degrade mucopolysaccharides is rapidly restored by lowering the $\mathrm{pH}$, and this reactivation does not require protein synthesis. Such $\mathrm{pH}$ dependence is not observed in cells from patients with genetic impairment of mucopolysaccharide degradation, such as the Hurler or Hunter syndromes.
We believe that this observation of an inactivation of a lysosomal function in cultured cells by raising the medium $\mathrm{pH}$, underlines the importance of a certain proton concentration for the normal function of this organelle. In support of this hypothesis we have found that antimalarial agents such as chloroquin or quinine inhibit mucopolysaccharide degradation much the same way as high medium $\mathrm{pH}$. These drugs are probably concentrated in the lysosomes and raise the intralysosomal $\mathrm{pH}$.

Our results show that the familiar problem of the relative importance of environment versus heredity is applicable to cells in culture as well as to the whole individual. Thus, by a minor manipulation of the environment, a condition mimicking storage disease can be induced in normal fibroblasts.

53. Haptoglobin in newborns. T. T. SALMi. Departments of Clinical Chemistry and Pediatrics, University of Turku, Turku, Finland.

It is known that in adults haptoglobin (Hp) is increased by infections and decreased by hemolysis. Data on newborns in this respect are very few. In this study observations were made on $\mathrm{Hp}$ levels in normal, icteric and infected newborns. Hp was determined by a modification of the method presented by Tarukoski (Scand. J. Clin. Lab. Invest., 18: 80, 1966).

The results were as follows: Normal newborns (250), 26.8 (7.041.2) $\mathrm{mg} / 100 \mathrm{ml}$; intrauterine infections (5l), 54.2 (30.5-120.2) $\mathrm{mg} / 100 \mathrm{ml}$; neonatal sepsis (18), $183.2(38.7-320.0) \mathrm{mg} / 100 \mathrm{ml}$; other neonatal infections (33), $60.7(25.3-264.0) \mathrm{mg} / 100 \mathrm{ml}$; Icteric newborns (80), $21.4(4.5-30.5) \mathrm{mg} / 100 \mathrm{ml}$.

The half-life of $\mathrm{Hp}$ was studied in patients in whom exchange transfusions were made. It varied from 6 to 30 hours. The halflife seemed to be shorter in patients with increased hemolysis. The results indicate that $\mathrm{Hp}$ estimations offer a new diagnostic aid in perinatal infections. The biological function of $\mathrm{Hp}$ in infections is still obscure.

54. The influence of the diet on the exocrine pancreatic function in premature newborn infants. G. Zoppr, G. ANDREotTI, F. Pajno-Ferrara, and D. Gaburro. University Pediatric Depart. ment of Verona, Verona, Italy.

The influence of the diet on the exocrine pancreatic function has been studied in premature newborn infants (gestational age $32-34$ weeks and birth weight $2.0-2.4 \mathrm{~kg}$ ), with the permission of the parents. In a previous communication we could show that premature newborn infants fed a formula containing $2 \mathrm{~g} / 100 \mathrm{ml}$ of soluble starch produce significantly more $\alpha$-amylase and less trypsin and lipase in comparison with premature newborn infants fed a similar isocaloric formula not containing starch, which was substituted by $2 \mathrm{~g} / 100 \mathrm{ml}$ of glucose. In the present paper we studied the influence of protein content of the diet on pancreatic enzyme activities in premature newborn infants. The subjects studied were divided into two groups: the first was fed a commercial infant formula containing $1.5 \mathrm{~g} / 100 \mathrm{ml}$ of protein and the second one a commercial skimmed milk containing 4.08 $\mathrm{g} / 100 \mathrm{ml}$ of protein. This group showed a significantly higher level of trypsin and lipase and no variations of $\alpha$-amylase activity. A clear correlation between higher protein intake and higher trypsin production may be observed, whilst on the other hand lipase and $\alpha$-amylase activities were not correlated with the diet composition. 
55. Studies on the metabolic adaptation in infants of diabetic mothers during the newborn period. J. Gentz and B. Persson. Department of Pediatrics, S:t Göran's Children's Hospital, Stockholm, Sweden.

Oxygen consumption $\left(\dot{\mathrm{VO}}_{2}\right)$, carbon dioxide production $\left(\dot{\mathrm{V}}_{\mathrm{CO}}\right)$ and respiratory quotient ( $R Q)$ have been determined in thermoneutral zone in 16 infants of diabetic mothers (8 IDM:s, 8 IGDM:s). All infants were given breast milk (the same amount per $\mathrm{kg}$ body weight) in increasing amounts with age. All were investigated at similar ages at four different occasions during the first week of life. Mean $\mathrm{VO}_{2}$ increased significantly with increasing age; in IDM: $\mathrm{s}$ from 5.21 to 6.29 and in IGDM:s from 5.56 to $7.19 \mathrm{ml} / \mathrm{kg} \cdot \mathrm{min}^{-1}$. $\mathrm{RQ}$ decreased during the first 24 hours of life and increased thereafter. The highest $R Q$ values, 0.98 in IGM and 0.92 in IGDM, were found at 7 days of age, when adequate caloric intake was reached and body weight was increasing. Immediately after intake of breast milk $\mathrm{V}_{2}$ increased significantly (up to $30 \%$ ), preceded by a marked increase in RQ. Peak $\dot{\mathrm{VO}}_{2}$ was reached approximately one hour after feeding and returned thereafter slowly to basal values. Plasma values for glucose, FFA and $\beta$-hydroxybutyrate were also significantly influenced by the amount of breast milk fed. At 24 hours of age there was an inverse correlation between $\beta$-hydroxybutyrate and $\mathrm{RQ}$ values $(r=0.86)$.

56. Provocation of growth hormone and insulin secretion in fullterm infants small for gestational age. P. Stubbe, J. Lerrrrrs, W. LEPPLA, and H. Wolf. Department of Pediatrics, University of Göttingen, Göttingen, Germany.

The postnatal response of growth hormone secretion in normal full-term infants varies considerably within the first two weeks of life. Of particular interest was the extension of such investigations on infants small for gestational age and the simultaneous determination of insulin. Both hormones play important roles in the immediate neonatal period. High growth hormone levels may be connected with liberation of energy from adipose tissue, whereas insulin may be involved with the tendency to hypoglycemia in infants small for gestational age. Forty normal full-term infants and 30 infants small for gestational age were investigated with i.v. glucose tolerance tests and i.v. arginine infusion on the $1^{\text {st }}, 4^{\text {th }}, 7^{\text {th }}$ and $14^{\text {th }}$ day of life. Growth hormone basic levels and the response to both tolerance tests resulted in decreasing growth hormone concentrations with increasing age. Infants small for gestational age showed higher concentrations in all groups. The insulin response after glucose injection and arginine infusion rose with increasing age in full-term infants whereas many infants small for gestational age did not respond at all and no gradual increase of insulin secretion in relation to age could be demonstrated. Thus, the growth hormone response to arginine and glucose was similar in full-term and small for gestational age infants and only quantitatively different. The insulin reaction after provocation was considerably different and gave no explanation for hypoglycemic episodes occasionally observed in small for gestational age infants.

57. Normal propionate metabolism in "nonketotic hyperglycinemia." E. R. BÁUMGARTNER, T. BRECHBÜHLER, and $\mathrm{H}$. WICK. University Children's Hospital, Basel, Switzerland.

Two unrelated newborns with a severe form of "nonketotic hyperglycinemia" were followed in our hospital. One of them died at the age of 18 months, the other at 3 weeks of age.
Clinical, dietary and biochemical studies of these patients suggested that the metabolic defect in their disease is entirely different from that in "ketotic hyperglycinemia" (propionic acidemia) and methylmalonic acidemia.

Therefore, propionate metabolism in the second patient was investigated in cultured skin fibroblasts and liver. Propionyl-CoA carboxylase was assayed by a modified method of Flavin and Ochoa (J. Biol. Chem. 229: 965, 1957). Conversion of propionyl$\mathrm{CoA}$ to methylmalonyl-CoA by the patient's fibroblasts and liver homogenate did not differ from that in normal controls. In addition, the conversion of methylmalonyl-CoA to succinyl-CoA was within the same range in both patient and control liver and fibroblasts, indicating that in our patient, not only propionylCoA carboxylase, but also methylmalonyl-CoA racemase and isomerase are functioning normally. These findings prove that "nonketotic hyperglycinemia" is a distinct disease, indeed, the primary enzyme defect of which is not yet known.

58. Gas chromatographic-mass spectrometric analysis of silylated oximes of urinary and plasma alpha-ketoacids in inborn errors of metabolism. H. J. STERNOwSKY and J. RoBoz. Department Pediatric Research, New York State Institute of Research in Mental Retardation; Department of Pediatrics and Department of Chemistry, Mt. Sinai School of Medicine, New York, and Universitaets-Kinderklinik, Hamburg, Germany.

Although gas chromatographic analysis of urinary and plasma phenolic acids is well established, no satisfactory method is available for the quantitative analysis of metabolically important $\alpha$-ketoacids.

In the method developed, alpha-ketoacids are extracted from urine with ethyl acetate, followed by conversion to oximes with hydroxylamine- $\mathrm{HCl}$, and finally silylation with bis-(trimethylsilyl)-acetamide containing $10 \%$ trimethylchlorosilane. Serum is deproteinized with ethyl alcohol, the alcohol is evaporated and the residue taken up in $0.1 \mathrm{~N} \mathrm{HCl}$. Extraction, conversion to oximes and silylation then is exactly the same as in urine. Quantitative gas chromatographic analysis with computer output is carried out using a 12-foot glass column filled with Chromosorb $\mathrm{W}, \mathrm{HP}, 100 / 120$ mesh, coated with $3 \%$ OV-17. The temperature is increased from $110^{\circ}$ to $220^{\circ}$ at a rate of $4^{\circ} / \mathrm{min}$.

The following $\alpha$-ketoacids were identified by computerized, high resolution mass spectrometry of the separated single gas chromatographic peaks: pyruvic acid, $\alpha$-ketobutyric acid, $\alpha$-ketovaleric acid, $\alpha$-ketoisovaleric acid, $\alpha$-keto- $\beta$-methylvaleric acid, $\alpha$-ketoisocaproic acid, $\alpha$-keto- $\gamma$-methiolbutyric acid, $\alpha$-ketoglutaric acid, and phenylpyruvic acid.

Applications are illustrated by comparing urines and plasmas of normal infants and children with those of patients with homocystinuria, before and after treatment with pyridoxine, and maple syrup-urine disease. The technique appears well-suited for the sreening and for the study of metabolic disorders involving amino- and $\alpha$-ketoacids.

59. Methyltransferase activities in human fetal tissues. W. v. Berg, J. A. Sturman, Niels C. R. Rärhä, and Gerald E. Gaull. Department of Pediatric Research, Institute for Basic Research, Staten Island, New York, USA; Children's Hospital University of Göttingen, Germany; Department of Pediatrics and Medical Chemistry, University of Helsinki, Helsinki, Finland.

Our previous studies of the transsulfuration of methionine to 
cysteine in the human fetus demonstrated that cystathionase activity was not measurable in the brain and liver, and that trace amounts of hepatic cystathionase, at most, were demonstrable immunochemically. Since the transsulfuration pathway was shut off, with accumulation of cystationine in liver but without accumulation of homocysteine, the methyltransferases involved in homocysteine metabolism were studied. Activity of $N^{5}$-methyltetrahydrofolate-homocysteine (MTHF) methyltransferase was found to be higher in fetal $(5.5-22.0 \mathrm{~cm}$ crown-rump length) human liver than in mature liver. The reverse is true for the activity of hepatic betaine-homocysteine $(\mathrm{BH})$ methyltransferase. Serine-tetrahydrofolate 5,10-hydroxy (STHF) methyltransferase activity in liver is not different at this period in development than in mature human liver. In brains from the same fetuses, there are, with increasing crown-rump-length, highly significant decreases in the activities of both NTHF methyltransferase and STHF methyltransferase, toward lower adult levels of activity. These findings, considered with the absence of cystathionase, suggest to us that the transsulfuration pathway is turned off for the further metabolism of homocysteine in favor of the folate- $B_{12}$ remethylation pathway. This pathway converts $N^{5}$-methyltetrahydrofolate, the major monoglutamic folate in liver and serum, to tetrahydrofolate. The latter reacts with serine on STHF methyltransferase to form 5,10-methylenetetrahydrofolate, a precursor for the de novo synthesis of thymidylate, which is uniquely required for DNA.

60. Pathogenetic mechanisms in lysinuric protein intolerance. O. Simel, J. Perheentupa, and J. K. Visakorpi. Children's Hospital, University of Helsinki, Helsinki, Finland.

Lysinuric protein intolerance (LPI, "familial protein intolerance") is an inborn error of metabolism characterized by renal leakage of basic amino acids, especially of lysine, and defective urea synthesis, resulting in hyperammonemia after amino nitrogen loading. The hyperammonemia can be abolished by simultaneous administration of arginine or ornithine. Plasma arginine, ornithine and lysine levels in fact are $1 / 3-1 / 2$ of that in controls. At present, 20 LPI-patients are known in Finland and one Finnish immigrant has been described from Sweden.

Urea cycle enzymes as well as carbamyl phosphate synthetase and glutaminasel are not decreased in livers of LPI-patients. We measured tubular reabsorption maxims of arginine and ornithine with constant infusion technique in LPI-patients and controls and found the $T_{m}$ to be of the same magnitude in both groups, though substantially less was reabsorbed at any lower plasma level in LPI-patients. During constant infusion of arginine or ornithine, the plasma level of the infused amino acid was clearly above that of controls, though more was lost into the urine. This strongly suggests, that liver cells in LPI share a common transport defect to that found in kidney tubuli, resulting in intracellular ornithine deficiency in these urea sythetizing cells. At present, we are studying the uptake of homoarginine as a nonmetabolizable model amino acid into the liver slices to show this transport defect in vitro.

61. Vitamin $B_{12}$-responsive methylmalonicacidemia (MMA). K. N. F. SHAW, R. KoGH, and G. N. DoNneld. Childrens Hospital of Los Angeles, and Department of Pediatrics, University of Southern California School of Medicine, Los Angeles, California, USA.

A 23-day-old premature (wt $1.96 \mathrm{~kg}, 36$ weeks gestation) was admitted because of poor feeding, weight loss, and hyperventilation. Dehydrated lethargic baby (wt $1.73 \mathrm{~kg}$ ) with intermittent apneic spells and hyperpnea, cyanosis and bradycardia. Liver and spleen normal. Poor Moro reflex and muscle tone, sustained clonus upon stimulation. Family history noncontributory.

Weak acetonuria. Blood $\mathrm{pH} 7.08 \& \mathrm{pCO}_{2} 20$. Two dimensional paper chromatograms showed an enormous MMA (18,000-23,000 $\mathrm{mg} / \mathrm{g}$ creatinine $(\mathrm{Cr})$; normal $2-5 \mathrm{mg}$ ). Urinary patterns of amino acids, sugars, phenols, imidazoles, indoles normal. Blood and CSF cultures negative. Blood count normal. Metabolic patterns in urine and serum from parents normal.

The patient became comatose and following respiratory arrest was maintained in a respirator for 2 days. Initially she was given $10 \%$ glucose IV and $400 \mu \mathrm{g}$ vitamin $\mathrm{B}_{12} / 24 \mathrm{hr}$ IM. MMA excretion decreased to $50-150 \mathrm{mg} / \mathrm{g} \mathrm{Cr}$ in 3 days, and clinical improvement was equally dramatic. Three days later she received a synthetic formula providing $0.1 \mathrm{~g}$ protein $/ \mathrm{kg} / 24 \mathrm{hr}$ at first, increasing stepwise to $1.0 \mathrm{~g}$ at 12 days, $1.5 \mathrm{~g}$ at 16 days, and 2.0 $\mathrm{g} / \mathrm{kg} / 24 \mathrm{hr}$ at 35 days after admission, with $10 \%$ glucose PO ad. lib. The $\mathrm{B}_{12}$ dose was increased to $4 \times 200 \mu \mathrm{g} / 24 \mathrm{hr}$ PO 28 days and $4 \times 150 \mu \mathrm{g} /$ day $P O 40$ days after admission. Serum $B_{12}$ 30 days after admission was $5500 \mathrm{pg} / 100 \mathrm{ml}$ (90-650 normal for adults). The patient weighed $2.70 \mathrm{~kg}$ at 11 weeks of age and has continued to progress well clinically. MMA excretion has remained in the range $140-500 \mathrm{mg} / \mathrm{g}$ Cr. Studies on $B_{12}$ intake, diet, and metabolic defect are proceeding.

62. Ketotic hypoglycemia: epinephrine insufficiency and decrease in alanine avaibility. P. C. Stzonenko, L. Paunier, M. B. VAllorton, and E. B. Marliss. Clinique Universitaire de Pediatrie, Laboratorie d'Investigation Clinique and Institut de Biochimie Clinique, Geneva, Switzerland.

Five children (H) who fulfill the criteria for ketotic hypoglycemia and five chidren $(C)$ who were investigated for a supposed but unproved abnormality of carbohydrate metabolism and hereafter referred to as controls were submitted to the following tests: $(I)$ The infusion of 2-deoxy-D-glucose induced in the $\mathrm{C}$ group clinical signs of hyperadrenergism, a rise of blood glucose (BG) and an increase in plasma renin activity (PRA) due to an enhanced release of epinephrine. No clinical signs of hyperadrenergism, no change of $B G$ and PRA were observed in the $\mathrm{H}$ group. Cortisol responses were normal in both groups. (2) A fasting period of $24 \mathrm{hr}$ was started after an IV glucagon test and ended by a second IV glucagon test. Ketosis appeared at the same time (16-21 hr of fast) in both groups. BG and cortisol responses were similar in the two groups during the fasting period and the two glucagon tests. (3) Blood alanine levels in the $\mathrm{H}$ group were lower after the fast and decreased more 30,60 , and $120 \mathrm{~min}(P<0.05)$ after the second glucagon injection.

It may be concluded that: $(I)$ ketotic hypoglycemia is due to an abnormal adrenal medulla response to an induced glucopenia; (2) a 24 hour fasting period does not differenciate between $\mathrm{C}$ and $\mathrm{H}$ groups, as far as ketosis and BG are concerned; (3) the deficiency of alanine as a substrate for neoglucogenesis is probably related to the deficient epinephrine secretion.

63. Studies on hypoglycemia in hereditary fructose intolerance. G. Van den Berghe, L. Hue, L. Corbeel, and H. G. Hers. University of Louvain, Louvain, Belgium.

In patients with hereditary fructose intolerance (HFI) fructose induces a profound hypoglycemia, which does not respond to the 
injection of glucagon. The present studies were undertaken to explain these phenomena. In normal children and in five HFI patients, the injection of glucagon $(100 \gamma / \mathrm{kg})$ provoked a $10-$ to 30 -fold increase of the urinary excretion of cyclic AMP (cAMP). After a fructose load $(250 \mathrm{mg} / \mathrm{kg}$ iv), this increase was almost completely abolished in HFI patients, but remained normal in the control children. Several data provide evidence that the reduced production of CAMP observed in HFI is secondary to the marked decrease of the level of ATP in the liver which is known to occur after a fructose load: (I) an acute increase of plasma methionine was observed after a fructose load in a patient with HFI; (2) animal experiments showed that, while in control mice, glucagon increased the hepatic concentration of cAMP from 0.8 nmoles $/ \mathrm{g}$ to about $50 \mathrm{nmoles} / \mathrm{g}$ after $3 \mathrm{~min}$, this increase was reduced to 2-7 nmoles $/ \mathrm{g}$ in mice, whose levels of ATP had been lowered. In all experimental conditions however, the increase of cAMP brought about by glucagon, was still sufficient to activate liver phosphorylase. This indicates that the reduction of cAMP production by the liver is not by itself a satisfactory explanation for the unresponsiveness to glucagon. A disturbance at the level of the action of CAMP in the liver in HFI was indicated by the fact that the injection of dBcAMP $(2 \mathrm{mg} / \mathrm{kg}$ iv) in two patients did not raise blood glucose after a fructose load, although it did in normal children. This might be explained by (1) the accumulation of F-I-P and (2) the depletion of $P_{1}$, which occur after a fructose load: we have found that in the presence of $5 \mathrm{mM} \mathrm{P}, 10 \mathrm{mM}$ F-I-P caused a $60 \%$ inhibition of liver phosphorylase, which was even more pronounced with lower concentrations of $P_{1}$.

64. Kinetics of glutamine intestinal absorption in phenylketonuric patients. M. Giovannini, E. Rrva, A. Mondino, and S. Fumero. II Clinica Pediatrica Università di Milano, Milan, Italy, and Istituto Ricerche Biomediche Antoine Marxer, Ivrea, Italy.

In phenylketonuric patients the plasma level of glutamine is lower than in normal subjects. Perry et al. (1970) have indicated that a chronical deficiency of glutamine in blood could be a possible cause of mental retardation. Moreover, they have supposed that the low glutamine plasma levels found in oligophrenic phenylketonurics might be caused also by a diminished absorption of glutamine from the gastrointestinal tract. In order to ascertain if the low level of plasma glutamine is due to a deficient intestinal absorption of this compound, an oral load of glutamine, proportional to the body surface, was administered to six treated phenylketonurics, four untreated phenylketonurics, and six normal subjects. Plasma samples were taken at 0 time, at $1 \mathrm{hr}$ and at $3 \mathrm{hr}$. Total amino acid determinations were performed on them, according to the ion exchange techniques described by Mondino (1968) and Mondino et al. (1971). The glutamine absorption kinetics are similar in all the 3 groups. The differences between the basal levels observed at 0 time for the three groups remain constant at the successive times of sampling. This demonstrates that the low plasma levels of glutamine in phenylketonurics are not due to an impaired intestinal absorption of this amino acid.

65. $\beta$-Mercaptolactate cysteine disulfide in the urine of two normal sisters. A. Niederwieser, P. GILIBERTI, and K. BAERLOCHER. University Children's Hospital, Zürich, Switzerland.

So far, $\beta$-mercaptolactate cysteine disulfide ( $\beta$-MLCD) has only been described in the urine of an adult mentally deficient patient (Ampola et al., 1969; Crawhall et al., 1969). We detected this unusual amino acid, a cystine analogue, in two obviously normal sisters. After isolation by preparative ion-exchange chromatography, high-voltage electrophoresis, and adsorption chromatography on Porapak $Q, \beta$-MLCD was identified by mass spectrometry of several derivatives and identification of the desulfuration products alanine and lactic acid by gas chromatography-mass spectrometry combination. The isolated $\beta$-MLCD contained no sulfoxide or sulfone. The metabolism of $\beta$-MLCD is presently studied using loading tests with methionine and cysteine.

66. Pyroglutamic aciduria-studies of a patient with chronic metabolic acidosis. L. HAGENFELDT, A. LARSSON, and R. ZETTERSTRöm. Department of Pediatrics, S:t Göran's Children's Hospital and Department of Clinical Chemistry, Serafimerlasarettet, Stockholm, Sweden.

In 1970 Jellum et al. described the fixst case of pyroglutamic aciduria. Their patient was a 19 -year-old mentally retarded male with spastic tetraparesis, metabolic acidosis and urinary excretion of pyroglutamic acid (5-oxo-proline). We have recently studied another patient with pyroglutamic aciduria. She is an one year old girl who developed severe metabolic acidosis on her third day of life. The patient has ever since required substitution with sodium bicarbonate to correct the acidosis. Her somatic and mental development have so far been normal, and she has no signs of neurological damage. The patient has normal glomerular filtration rate, urinary acidification, tubular reabsorption of bicarbonate and urinary excretion of $\alpha$-amino acids. In the urine we were able to identify the presence of large amounts of $\mathrm{L}$ pyroglutamic acid. The excretion of this acid was constant when the protein intake was varied. Approximately $6 \mathrm{~g}$ pyroglutamic acid was obtained in the urine per $24 \mathrm{hr}$. The urea synthesis appears to be normal. These findings indicate a defect in the $\gamma$-glutamyl cycle for amino acid transport which was recently postulated by Orlowski and Meister. The tentative location of this defect is the renal break down of pyroglutamic acid catalysed by 5 -oxoprolinase. The metabolic acidosis might be caused by the shunting of $\alpha$-ketoglutarate from the tricarboxylic acid cycle via glutamate to pyroglutamate.

67. Human hypoxanthine-guanine phosphoribosyl transferase isozyme patterns. V. M. Der Kaloustian, B. AwDEh, R. Hallal, and N. Waked. American University Medical Center, Beirut, Lebanon.

Hypoxanthine-guanine phosphoribosyl transferase (HGPRT) catalyzes the transfer of the 5-phosphoribosyl moiety of magnesium 5-phosphoribosyl-1-pyrophosphate (MgPRPP) to guanine and hypoxanthine to form their corresponding ribonucleotide derivatives, guanosine $5^{\prime}$-monophosphate (GMP) and inosine $5^{\prime}$ monophosphate (IMP). Elucidation of the structure of the normal enzyme would provide a basis not only for understanding the genetic lesion(s) producing altered or absent enzyme activity but also knowledge essential to the eventual study of the regulation of its synthesis. Isoelectric focusing was performed on normal male human erythrocyte hemolysates with polyacrylamide gel electrophoresis according to the procedure of Awdeh et al. The run lasted $48 \mathrm{hr}$. The $\mathrm{pH}$ range was $5-7$. The method of Der Kaloustian et al of combined electrophoresis and autoradiography was applied and three bands were found on the x-ray film, cor- 
responding to three HGPRT isozymes. Moreover, the gels were cut into $2 \mathrm{~mm}$. pieces which were eluted in buffer. The reaction for HGPRT was then run. Three enzymatic peaks were discovered, corresponding to the dark bands of the $x$-ray films in the autoradiography experiments. The isoelectric points of the three peaks using $\mathrm{pH}$ 5-7 range ampholytes were: peak $\mathrm{I}, \mathrm{pK}_{\mathrm{f}}$ 6.4; peak II, $\mathrm{pK}_{1}$ 6.15; peak III, $\mathrm{pK}_{1}$ 6.02. Although multiple electrophoretic forms of one enzyme may be genetic in origin, the isoenzymes of HGPRT appear to result from posttranscriptional nongenetic alterations.

68. Identification of heterozygotes of fucosidosis. R. GATTI, and P. Durand. Third Department of Pediatrics, G. Gaslini Hospital, Genoa, Italy.

The metabolic derangement in fucosidosis is a deficiency of $\alpha$-fucosidase which catalyzes the cleavage of fucose from fucolipids and fucopolysaccharides.

After our two cases of fucosidosis, six other cases have been detected. A family investigation in the family studied by us showed that two other subjects have been affected by a similar disease.

Assay for the $\alpha$-fucosidase using serum and leucocytes preparations were attempted with the artificial substrate ( $p$-nitrophenyl$\alpha$-L-fucoside). Serum $\alpha$-fucosidase activity in normal subjects averaged $296-608 \pm 79$ nmoles of substrate cleaved $\mathrm{ml}$ serum $/ \mathrm{hr}$ at $37^{\circ}$. Leucocytes $\alpha$-fucosidase in normal subjects averaged $65-136 \pm 20$ nmoles of substrate cleaved $/ \mathrm{mg}$ protein $/ \mathrm{hr}$ at $37^{\circ}$ The mother of our patients affected by fucosidosis had a serum $\alpha$-fucosidase of $110 \mathrm{nmoles} / \mathrm{ml} / \mathrm{hr}$ and a leucocytes $\alpha$-fucosidase of $34 \mathrm{nmoles} / \mathrm{mg} / \mathrm{hr}$. Serum and leucocyte enzyme assays may be useful for the identification of carriers of fucosidosis and lead to the preventive control of such diseases.

69. Detection of specific antibodies in different immunoglobulin classes. M. Just, A. Buergin-WolfF, and R. Hernandez. Department of Pediatrics, University of Basel, Childrens Hospital, Basel, Switzerland.

Serum antibody-testing against infectious agents gives very often no reliable answer to the question, if an infection is recently acquired or not-an important question for instance in cases of rubella-contacts during first months of pregnancy. Serum antibodies found in the sera of newborns are the result either of passive transfer from the mother or of a fetal infection.

By determination of specific serum antibodies in the different classes of immunoglobulins it is possible to differentiate between late or recently acquired infection or between passively transferred or actively produced antibodies in the newborn.

Two simple methods for determination of specific antibodies in different immunoglobulin classes - especially in the IgM-fraction-were developed in our laboratory: (1) Separation of serum antibodies by gel filtration on agarose columns followed by determination of specific antibodies in the different fractions. Data especially on specific rubella antibodies are presented. (2) Covalent binding of a soluble antigen to a non-soluble material (agarose beads) allows the rapid determination of specific antibodies in different immunoglobulin classes by a fluorescence method. Preliminary results with this technique, which can be performed theoretically with any soluble antigen-antibody-system, will be presented.

Such a method for determination of specific IgM-antibodies rould be useful for routine screening of newborns.
70. Humoral antibodies against Candida albicans. A study of the diagnostic value of Candida precipitins and agglutinins in Candida colonization and Candida infections with and without immunologic incompetence. F. BLÄKER, and H. $\mathrm{H}$. HELLWEGE. Universitäts-Kinderklinik Hamburg-Eppendorf, Hamburg, Germany.

For testing the diagnostic value of immunologic examinations in systemic Candida infections we investigated Candida precipitins and agglutinins in sera of healthy newborns, infants, children, and adults (100 subjects), of 10 patients with Candida infections and intact immune defence, 4 patients with candida infections during cytotoxic treatment, 3 patients with chronic granulomatous candidiasis, 10 patients with allergic asthma, and 4 patients with congenital agammaglobulinaemia.

The titers of Candida agglutinins in peripheral blood increased with age. In healthy older children and adults only agglutinins could be found (IgM antibodies). They were detectable in all but two sera.

In patients with Candida infections and not impaired immunity the agglutinins were not significantly increased. But precipitating antibodies could be found in all cases, also in those treated with cytotoxic drugs. According to this, the differentiation between apathogenic candida colonization and candida infection-sometimes very difficult to achieve by means of clinical and mycological criteria-can be made with a high degree of certainty.

Patients with chronic mucocutaneous candidiasis and partial cellular immune defects had high titers of both precipitating and agglutinating antibodies but not delayed hypersensitivity against Candida albicans.

Falsely positive results occurred in patients with hyperreagibility of immune system, f.i. in allergic states like asthma bronchiale.

Patients with agammaglobulinaemia and candida colonization and infection had neither agglutinating nor precipitating antibodies in their blood before treatment with gammaglobulin preparations was started.

71. Heinz body formation in erythrocytes of newborn infants: the role of hemoglobin content in red cell membranes. W. Schröter and W. Tillmann. Department of Pediatrics, University of Hamburg, Hamburg, Germany.

Erythrocytes of newborn infants, incubated with acetylphenylhydrazine, produce Heinz bodies faster than do erythrocytes of adults incubated under the same conditions. Intact red cell membranes (ghosts) which were prepared from both adult and newborn erythrocytes also produce Heinz bodies when exposed to acetylphenylhydrazine. Ghosts of red cells of newborn infants contain more hemoglobin and produce Heinz bodies faster than the ghosts of adults. Ghosts prepared from erythrocytes of adults and newborn infants, which were suspended for $20 \mathrm{hr}$ in their own plasma or in that of the other group before ghost preparation, contain more hemoglobin than ghosts prepared from fresh erythrocytes. The highest concentration of hemoglobin is found in the membranes of red cells of newborn infants incubated in the plasma of adults. This finding correlates well with the enhanced susceptibility of these ghosts to acetylphenylhydrazine. We suppose that the ability of faster formation of Heinz bodies of erythrocytes of newborn infants both in vitro and in vivo is due to the higher concentration of hemoglobin in their membranes. 
72. The "early anemia", its relation to the suckling period, rapid growth, and iron availability. K. Halvorsen and S. HALVORSEN. Pediatric Research Institute, Rikshospitalet, Oslo, Norway.

In several species, including man, there is a postnatal drop in hemoglobin $(\mathrm{Hb})$ and hematocrit $(\mathrm{Ht})$ termed the "early" or "physiological anemia". Rapid growth, expansion of the plasma volume, unresponsiveness of the erythropoiesis regulatory system and incapacity of the blood forming organs to keep up with the rapidly expanding blood volume have been proposed as causative factors. The rabbit was used as an experimental animal. Low $\mathrm{Hb}$ and $\mathrm{Ht}$ values developed in the most rapidly growing animals towards the end of the suckling period. The red cell volume (RCV)/kg body weight was inversely proportional to the weight increase. Following weaning the reticulocytes increased and the $\mathrm{Hb}, \mathrm{Ht}$ and $\mathrm{RCV} / \mathrm{kg}$ reached adult levels within 2 weeks. Based on this and previous studies in other species the following characteristics of the "early anemia" may be outlined: The low $\mathrm{Hb}$ values occur: (1) during the most intensive growth period; (2) within weeks or months after birth when the neonates are exclusively milk fed; (3) the lowest values are found at the end of the suckling period; and (4) they are rapidly restored to adult levels following weaning. The rabbit has large iron stores in the liver at birth. Iron is still present in the liver at the time when the $\mathrm{Hb}$ fall below adult levels between the tenth and twentieth day of life. Parenteral iron, however, completely normalizes the $\mathrm{Hb}-\mathrm{Ht}$ levels and keep the $\mathrm{RCV} / \mathrm{kg}$ higher than in the adult rabbits even in the most rapidly growing animals. The "early anemia" in the rabbit is thus an "iron responsive anemia" although the young rabbit is not iron depleted. This is another example that the rate of erythropoiesis is not only depending upon iron stores but upon the availability of the iron in the blood forming organs. It is postulated that a similar situation exists in other species. The young rabbit is capable of keeping the peripheral blood values within adult limits in spite of a very rapid growth.

73. Some biological characteristics of the leukaemic cells in acute lymphoblastic leukaemia. L. Massimo, M. Governa, C. Rosanda, I. Franchini, and G. P. Tonda. Paediatric Department G. Gaslini and Industrial Medicine Department, University of Genoa, Genoa, Italy.

It is assumed that the presence of surface immunoglobulins (Ig) can be used as a marker for bone marrow (B) lymphocytes while their lack demonstrates that thymus $(T)$ cells are concerned. Recent studies show that chronic lymphocytic leukemia (c.1.1.) is a neoplastic disease of B cells. We examined the blood of a 45-year-old woman suffering from a very acute lymphoblastic leukemia (a.1.1.): $90 \%$ of blood lymphocytes had Ig on their surface in a ring pattern while PHA responsiveness was absent. In this case the leukemic process was due to the abnormal proliferation of B-lymphocytes as it is usually observed in c.l.l.

We have studied 16 children with a.l.1. at the onset and not yet treated, with the following tests: membrane immunofluorescence of the lymphocytes from peripheral blood and in few cases also from bone marrow; lymphoblastic transformation by PHA of blood and bone marrow. We have taken into account also the number of peripheral blast cells per $\mathrm{mm}^{3}$ and the clinical response to a preliminary successive 7 -day treatment with $\mathrm{L}$-asparaginase. Most of the blood and bone marrow lymphocytes did not show any detectable amount of Ig in their surface, while
PHA-blastogenesis was good. This behavior shows that in all the children examined the disease was due to a disturbance of $T$ lymphocytes.

74. Investigations in "early normal puberty" (Seckel) and con stitutionallay delayed adolescence. J. R. BIERICH. Universitaets-Kinderklinik Tuebingen, Tuebingen, Germany.

Twenty-six patients with constitutionally delayed adolescence (I) and 15 patients with "early normal puberty" (II) were repeatedly investigated. In I longitudinal growth, skeletal, and sexual maturation were equally retarded. Height, development of testes and pubes and urinary 17-KS and testosterone were well correlated $(r>0.7)$. Boys showing a bone age $\geqslant 12$ years experienced normal puberty. No criteria of endocrine deficiencies could be detected (HGH, thyroid). Positive correlations between body height, skeletal and sexual maturation were found as well in the patients with (II). Prediction of adult height yielded normal values in both of the groups. In numerous cases of (I) and (II) dominant inheritance could be demonstrated. It is assumed that the deviations of growth velocity and skeletal maturation in the two syndromes are caused by a genetically determined different responsiveness of the growing tissues, particularly the bones, to the effects of the growth promoting hormones. The accelerated or, resp., retarded onset of puberty always correlated with accelerated or retarded skeletal maturation and most probably is causally connected with it. In contrast to that, in patients with true precocious puberty there is a gap between the degree of osseous development and the more pronounced sexual precocity. The accelerated skeletal maturation in these cases is the result of the precociously secreted sexual steroids.

75. Urinary hydroxyproline excretion in different forms of stunted growth. U. Genscher, W. Teller, H. Burkhard, and K. Rommel. Departments of Pediatrics, Endocrinology and Metabolism and Section of Clinical Chemistry, Center of Internal Medicine and Pediatrics, University of Ulm, Ulm, West Germany.

The hydroxyproline excretion in 24-hr urines was determined in 10 growth hormone deficient, 2 hypothyroid, 1 growth hormone insensitive, and 12 primordial dwarfs between 4 and 19 years of age. The normal range of urinary hydroxyproline excretion at different ages was determined in 40 children aged between 3 and 14 years. All subjects were placed on a hydroxyproline free diet before and during urine collections. There was no difference of hydroxyproline excretion (expressed as $\mathrm{mg} / \mathrm{m}^{2}$ body surface/24 hr) between primordial dwarfs and normal children of the same age. Children with pituitary and hypothyroid dwarfism had a decreased excretion of hydroxyproline. Giving growth hormone and/or thyroid hormone raised the hydroxyproline excretion to normal.

During childhood urinary hydroxyproline excretion $\left(\mathrm{mg} / \mathrm{m}^{2}\right.$ body surface $/ 24 \mathrm{hr}$ ) provides a valuable means for distinguishing between endocrine dwarfism (low excretion) and nonendocrine (primordial) dwarfism (normal excretion). In older adolescents and adults it is less reliable.

76. Plasma TSH (thyroid-stimulating hormone), HGH (growth hormone), TI (thyroxine iodine) cortisol and blood sugar response to synthetic TRH (thyrotropin-releasing-hormone) in children. J. Girard, U. Bühler, P. Kindler, J. B. BaumanN, 
M. StahL, and P. W. NARS. University Children's Hospital Basel, Basel, Switzerland.

TRH was administered intravenously in a dose of 100 or 200 $\mu \mathrm{g}$ to 35 children aged 3 days to 17 years with suspected pituitary or thyroid disorders. Patients without endocrine disorders served as controls. Blood sugar did not change significantly. A consistent pattern of growth hormone and cortisol, reflecting a response to TRH was not observed. The elevated values at the beginning of the test, which subsequently decreased indicate a stress response. TI values did not change significantly in any of the children tested. TSH showed a prompt increase with a maximum value 15-45 min after injection. In patients with known or suspected thyroid disorders the pattern of TSH was significantly different from the mean values given in the table.

\begin{tabular}{lrrrrrrrr}
\hline & $-15^{\prime}$ & $15^{\prime}$ & \multicolumn{1}{c}{$30^{\prime}$} & \multicolumn{1}{c}{$45^{\prime}$} & $60^{\prime}$ & $2 \mathrm{hrs}$ & $6 \mathrm{hrs}$ & $24 \mathrm{hrs}$ \\
\hline TSH $\mu \mathrm{U} / \mathrm{ml}$ & 2.4 & 15.0 & 13.1 & 13.4 & 9.8 & 6.6 & 3.0 & 2.4 \\
$\pm 1 \mathrm{sD}$ & 1.6 & 9.8 & 9.4 & 8.3 & 5.4 & 4.1 & 2.6 & 2.0 \\
& & & & & & & & \\
TI $\mu \mathrm{g} \%$ & 4.7 & 4.8 & 4.5 & 4.6 & 4.8 & 4.6 & 4.7 & 5.0 \\
$\pm 1 \mathrm{sD}$ & 1.3 & 1.2 & 1.0 & 1.0 & 1.3 & 1.2 & 1.6 & 1.0 \\
& & & & & & & & \\
HGH ng $/ \mathrm{ml}$ & 7.5 & 6.7 & 5.4 & 5.0 & 5.3 & 6.0 & 4.6 & 1.3 \\
$\pm 1 \mathrm{sD}$ & 11.4 & 7.4 & 7.5 & 7.3 & 6.4 & 10.5 & 5.1 & 1.0 \\
Cortisol & 40.2 & 40.9 & 33.8 & 31 & 34.2 & 32.3 & 31.2 & 28.3 \\
$\mu \mathrm{g} \% \pm 1 \mathrm{sD}$ & 15.6 & 13.4 & 13.3 & 10.2 & 13.9 & 11.4 & 13.3 & 7.7 \\
\hline
\end{tabular}

From the present investigation it appears that intravenous injection of TRH to children only provokes a TSH response and does not affect the other parameters measured.

77. Reduced proton flux across epithelial cells, a general phenomenon in cystic fibrosis (CF)? D. KaISER. UniversitätsKinderklinik Bern, Bern, Switzerland.

From previous investigations of single sweat glands we concluded that the normal duct would not only reabsorb $\mathrm{Na}$ but also possess an acetazolamid-sensitive mechanism for proton-secretion towards the lumer accounting for reabsorption of bicarbonate and maintenance of a transepithelial $\mathrm{pH}$ gradient (lumen acid). In the acetazolamid-treated adult and the newborn child $\mathrm{H}$ ion secretion is largely reduced leading to $\mathrm{pH}$ gradients near zero and little reabsorption of bicarbonate, and in both cases $\mathrm{Na}$ and $\mathrm{K}$ rich sweat is produced. From the defect in proton secretion and cation excretion one might suspect an interrelationship of both processes in that $\mathrm{H}$ secretion is essential for ductal $\mathrm{Na}$ reabsorption and $\mathrm{K}$ excretion. If this would apply to $\mathrm{CF}$ glands one would expect low proton and high bicarbonate values in CF sweat. Our measurements, performed in single glands with nanoliter electrodes, showed: $\langle I\rangle$ alcaline $\mathrm{pH}$ values at all sweat rates, i.e. abolished transepithelial gradient; (2) largely reduced reabsorption of bicarbonate.

We conclude that in CF proton secretion across the sweat gland duct into the lumen is reduced. This might be responsible for the relatively high negativity of the lumen $(-54 \mathrm{~m} \mathrm{~V}$ instead $-4 \mathrm{mV}$ normal). Consequently active reabsorption of $\mathrm{Na}$ takes place against a steeper electric gradient leading to high $\mathrm{Na}$ in final sweat whereas $\mathrm{K}$ excretion down this gradient is facilitated. As the pancreatic defect might be interpreted by reduced reabsorption, it is possible that diminished transepithelial proton flux is an essential feature of $\mathrm{CF}$.
78. The abnormality of the $\beta$-glucuronidase activity in cystic fibrosis of the pancreas (CF): a new aspect of the disease. $S$. Nordio, A. G. Marchi, M. A. Mangiarotti-Marchi, and G. Mastella. Institute of Child Health, University of Trieste, Trieste, Pediatric Clinic University, Genoa, and Pediatric Hospital, Verona, Italy.

In the recent years $\beta$-glucuronidase activity has been studied in the skin and the white cells of blood of the patients with CF. An abnormality of this enzyme activity has been found.

The AA pursued the investigations on the $\beta$-glucuronidase activity of lymphocytes of both homozygotes and heterozygotes of CF. A statistically significant reduction of this activity has been demonstrated on the phytohaemoagglutinine-stimulation of lymphocytes. Without this stimulation the enzyme activity is, on the contrary, higher then in control subjects. The results are discussed from the pathogenetic and the genetic points of view. With regard to the pathogenetic problem a few researches were performed on the influence of the Triton $\mathrm{X}-100$ on the release of the enzyme from the cells, on the ratio between enzyme activity of the in vitro cultured lymphocytes and the culture fluid, on the influence of the CF serum on the $\beta$-glucuronidase activity of normal lymphocytes.

79. Lipiodol test with an iodide-selective membrane-electrode for examination of fat malabsorption. K. Gyurkovits and D. Boda. University Children's Hospital, Szeged, Hungary.

Measurement by an iodide-selective membrane-electrode proved to be a simple method to check urinary iodide-excretion, and more advantageously the increase of iodide activity in blood following peroral Lipiodol administration.

The method was used in 60 children, in cases with complete, partial or no fat malabsorption.

The test is promising in application in the screening of clinical conditions with defective fat malabsorption, especially mucoviscidosis.

80. Screening methods: microbiological assays-enzyme spot test for galactosemia. R. Gitzelmann. Laboratory for Metabolic Research, Department of Pediatrics, University of Zürich, Kinderspital, Zürich, Switzerland.

The bacterial "inhibition assay" was introduced in 1961 as a screening test for phenylketonuria in the newborn and has since won world-wide acceptance. It is based upon the inhibition of normal bacterial growth by an antimetabolite; this inhibition is offset specifically by one amino acid sought in the blood which has been spotted on filter paper. Such amino acids are: phenylalanine; leucine; histidine; methionine; or lysine. "Multiple bacterial tests" are also available. The "metabolite inhibition assay" of galactose makes use of an Echerichia coli mutant (transferaseless); its growth is inhibited by galactose. This test therefore will discover hypergalactosemia either due to galactose I-phosphate uridyltransferase deficiency or to galactokinase deficiency. It is being replaced by yet another microbiological assay designed by Paigen (unpublished): in the absence of galactose from the medium, an epimerase-less $E$. coli mutant is lysed by a phage; lysis is prevented by galactose, and bacterial growth will thus signal hypergalactosemia. The test can be expected to detect galactose 1-phosphate as well and has done so in a case of UDPgalactose 4-epimerase deficiency. The enzyme spot screening test for galactosemia has been adapted to blood collected and dried on filter paper and is now widely used. Presence of transferase is 
indicated by fluorescence emitted by NADPH. The test is simple and fast, but it is handicapped by a high incidence of "lack of fluorescence" caused by factors other than transferase deficiency. This difficulty is partially overcome by the use of DEAE-paper for the spotting. Other enzyme tests have been described.

81. Thin layer and paper chromatography with blood (spots). R. ScHöN. Universitäts-Kinderklinik, Wien, Vienna, Austria.

The eminent advantage of chromatographic methods is the detection of a great number of amino acids by only one working operation. This means at least theoretically that all metabolic disorders accompagnied by hyperaminoacidemia could be detected by chromatography (CHR), whereas Guthrie tests discover only a limited number of hyperaminoacidemias.

Methods available to mass screening are paper chromatography (PC) and thin layer chromatography (TLC). Whole blood, dried on filter paper, or serum is used for examination.

The advantages of TLC as contrasted to PC are higher sensitivity and shorter running time, those of PC simple handling and cheapness. Advantages in using serum are simple handling (especially in TLC), those of dried blood spots easier mailing and stability of the amino acids.

Screening centres using only CHR for newborn mass screening with good success are Montreal and Manchester. Massachusetts, Warzaw and Vienna, using CHR beside Guthrie tests, could not find one case with CHR which was not detected with Guthrie tests within 260,000 parallel examinations.

In our experience, in CHR the range of findings is wider and sensitivity for some amino acids (methionine, histidine) lower than in Guthrie tests, which are used in our laboratory additionally to galactosemia for the five most frequent and/or important hyperaminoacidemias. Diseases detectable by CHR but not by Guthrie tests seem to be very rare. It therefore appears questionable whether the advantage of CHR outweighs the disadvantage in mass screening for hyperaminoacidemias.

82. Newborn screening for amino acids, sugars, etc. in urine.

H. J. Bremer. Department of Metabolic Disease II, Center of

Internal Medicine and Pediatrics, University of Ulm, Ulm, West Germany.

For screening of anomalies of amino acid metabolism in urine one- and two-dimensional thin layer chromatographic methods may be used. The urine is collected and mailed in capillaries. I $\mu \mathrm{l}$ is spotted to precoated cellulose plates (Merck) and developed twice up to $8 \mathrm{~cm}$ with the solvent 1-butanol-acetone-acetic acidwater $(35: 35: 10: 20)$. If an increased excretion of more polar amino acids is suspected the following solvent gives better separation of this group: tert-butanol-methylethylketone- $\mathrm{NH}_{3}-\mathrm{H}_{2} \mathrm{O}$ $(50: 30: 10: 20)$. The plates are normally stained with a mixture of ninhydrin and isatine. Multiple staining techniques are possible.

Amino acids of urines with abnormal excretion are separated two-dimensionally by the technique described in Clin. Chim. Acta, 35: 345 (1971). This method allows a separation of almost all important amino acids of the urine without desalting and a tentative diagnosis.

If one is performing the Guthrie or Beutler test for detecting galactosemia and galactokinase deficiency an urine screening for abnormal sugar excretion is only necessary for selected cases. Urine without desalting may be chromatographed two-dimensionally on precoated plates of extra fine silica gel with fluorescence indicator (Merck) with the solvents 1-butanol-isopropanol-
$\mathrm{H}_{2} \mathrm{O}$ (containing $100 \mathrm{mg}$ boric acid/100 ml) and acetonitril- $\mathrm{H}_{2} \mathrm{O}$ (85:15). Calor reagent: $0.5 \mathrm{~g}$ naphthalene-1,3-diol in $100 \mathrm{ml}$ ethanol:conc. sulfuric acid $(95: 5)$. All diagnostically important urinary sugars are separated.

83. Screening for organic acids in urine. H. WICK, T. BreCHBüHLER, R. BAumgartNer, and R. BÉDoucha. University Children's Hospital, Basel, Switzerland.

A high voltage apparatus from CAMAG (Muttenz, Switzerland) was used for the screening of organic acids in urine. Urine samples corresponding to $15 \mu \mathrm{g}$ creatinine were applied. After a run of $13 \mathrm{~min}$ the paper was well dried and cut at the start line. The part corresponding to the cationic side was stained with ninhydrine for amino acids. The other part was first sprayed with bromophenolblue, suspicious fractions were then marked with a pencil and the strip was stained with fastblue $B$ spray (FLUKA).

Bromophenolblue is a $\mathrm{pH}$ indicator and reacts with all acids present in sufficiently high concentrations, but it is not very sensitive. Fast blue is a diazonium salt, is more sensitive and reacts in a more specific manner with many clinically important acids, such as aromatic acids, some ketoacids and methyl malonic acid.

84. Mass screening of dried blood specimens to detect inborn errors of metabolism in newborn infants in the USA. W. H. Murphey, and R. Guthrie. Department of Pediatrics, State University of New York at Buffalo and the Children's Hospital, Buffalo, New York, USA.

Mass screening of newborn infants for phenylketonuria (PKU) is conducted in each of the 50 states in the USA by private and public health laboratories. All but one of the state laboratories utilize the Guthrie Bacterial Inhibition Assay (BIA) for blood phenylalanine; one state and some private laboratories utilize fluorometric or chromatographic techniques. Approximately $90 \%$ of the 3.5 million infants born each year are tested with specimens collected during the first week of life; over-all, the incidence of PKU is approximately $1: 14,000$. Since 1964, four area screening laboratories (Massachusetts, Oregon, western New York, and southern California) have utilized the same dried blood specimens to test for other inborn errors of metabolism. Recently, two other PKU-screening laboratories have initiated such multipletest programs. These programs include tests for abnormal concentrations of tyrosine, leucine, methionine and/or histidine by BIA procedures and tests for galactosemia by means of microbiological assays of galactose and/or of transferase enzyme activity by means of the "Beutler" test. Preliminary screening projects have been conducted to detect arginino-succinic aciduria (ASA) and orotic aciduria $(\mathrm{OAU})$ by techniques which employ bacterial auxotrophs to detect deficiencies in the catalytic activity of specific enzymes in exythrocytes. Screening programs for deficiencies in enzyme inhibitor $C^{\prime} 1$ esterase inhibitor and $\alpha-1$ trypsin in hibitor in serum) are underway. The results of these blood screening programs as of June 30,1972 are as follows.

\begin{tabular}{|c|c|c|c|}
\hline & $\begin{array}{c}\text { No. } \\
\text { detected }\end{array}$ & Disease & No. tested \\
\hline \multirow[t]{2}{*}{ Phenylalanine } & 136 & Classical PKU & $1,757,619(1: 12,900)$ \\
\hline & 74 & Nonclassical PKU & $1,757,619(1: 23,700)$ \\
\hline Leucine & 5 & MSUD & $1,429,790(1: 286,000)$ \\
\hline Methionine & 6 & Homocystinuria & $957,514(1: 159,000)$ \\
\hline Histidine & 2 & Histidinemia & $96,674(1: 48,300)$ \\
\hline Galactosemia & 13 & Transferase def. & $1,075,155(1: 82,700)$ \\
\hline ASA & 1 & ASA lyase def. & $276,928(?)$ \\
\hline
\end{tabular}


85. Mass screening of urine specimens to detect metabolic and transport disorders in newborn infants. W. H. MURPHEY. Department of Pediatrics, State University of New York at Buffalo, Children's Hospital, Buffalo, New York, USA.

Mass screening programs to detect phenylketonuria and certain other metabolic diseases in newborn infants utilize blood specimens collected on filter paper, dried, and mailed to a central laboratory. Some metabolic and transport disorders can be more readily detected by the use of urine specimens. Two large-scale screening programs are being conducted (Massachusetts, USA, and New South Wales, Australia) which utilize urine specimens collected on filter paper by the infant's parents and mailed to the testing laboratory. These specimens are tested by punching one or more discs from the urine-impregnated filter paper with a paper punch and submitting these discs to a series of chemical spot-tests, one-dimensional chromatographies, and if necessary, high voltage electrophoresis and two-dimensional chromatography.

Aside from transient tyrosinuria and generalized aminoaciduria, the results of these screening programs include the detection of such abnormalities as cystinuria, histidinemia, prolinuria or iminoglycinuria, and Hartnup disease at frequencies greater than $1 / 20,000$. In addition, individual cases of abnormalities such as argininosuccinic aciduria, nonketotic hyperglycinemia, ketotic hyperglycinemia (proprionic aciduria) hyperlysinemia, hyperornithinemia, Fanconi syndrome and cystathioninuria have been detected among the more than 300,000 infants tested in these programs.

86. Screening results in eight countries of western Europe. E. SCHMID-RürER. University Kinderklinik, Heidelberg, West Germany.

The Public Health Committee of the Council of Europe invited a Working Party to collect information on newborn screening results and on the incidence of hereditary disorders of metabolism in eight European countries. Represented were Belgium, Denmark, France, the Federal Republic of Germany, Ireland, the Netherlands, Switzerland and the United Kingdom. The beginning of screening in these countries differed as did the test methods and the evaluation of the results. For these reasons this first report does not permit a close comparison to similar studies with standarized test methods in non-European countries. The collective results of the eight European countries are shown in the table:

\begin{tabular}{lrcc}
\hline \multicolumn{1}{c}{ Screening for } & No. tested & \multicolumn{2}{c}{$\begin{array}{c}\text { No. detected } \\
\text { Pathologic ratio }\end{array}$} \\
\hline Phenylketonuria & $4,457,491$ & 544 & $1: 8,179$ \\
$\begin{array}{l}\text { Maple syrup urine } \\
\text { disease }\end{array}$ & 729,822 & 9 & $1: 81,091$ \\
Galactosaemia & 676,258 & 11 & $1: 61,478$ \\
Histidinaemia & 215,503 & 18 & $1: 11,972$ \\
Homocystinuria & $1,110,874$ & 6 & $1: 185,145$ \\
Tyrosinosis & 385,450 & $1 / 654^{1}$ & $1: 385,450$ \\
\hline
\end{tabular}

1 Transient forms.

87. Postnatal screening for inborn errors of metabolism in Poland. K. Boźkowa, B. Cabalska, N. Duczý́ska, and Z. Grodzka. National Research Institute for Mother and Child, Warsaw, Poland.
Screening tests for early detection of inborn errors of metabolism were carried out. Samples of blood and urine dried on filter paper were used. The work was done with the use of the following methods: (1) Guthrie bacterial inhibitions assay for phenylalanine, methionine, histidine and tyrosine; (2) one-dimensional paper chromatography of amino acids acc. to Efron; (3) Beutler and Baluda fluorescent test for galactosemia; (4) multiplied urine screening test acc.to Berry. Guthrie test for phenylalanine was performed in 700 thousand newborn infants. Positive results ( $>4 \mathrm{mg} / 100 \mathrm{ml}$ ) were found in 438 cases i.e. $0.06 \%$. Out of this number in 315 cases of transient phenylalaninemia of newborn period and early infancy were diagnosed. In the group of 99 cases of persistent phenylalaninemia confirmatory estimations, clinical course of treatment, and verifying examinations allowed to classify: 85 cases of classical PKU, 8 cases of atypical PKU, and 6 cases of persistent mild phenylalaninemia non PKU. Guthrie test for methionine was carried out in 211 thousand newborns. No case of metabolic disturbances in sulphur amino acids was found. Lately Guthrie tests for histidine and tyrosine were introduced to the program. In about 30 thousand of newborn infants tested, a relatively high percent of abnormal tests was found. The cases are under observation and control examinations. Out of other method performed the test of Beutler and Baluda deserves attention. Among 162,000 tests performed 5 cases of galactosemia and 4 heterozygotes were found. The screening test which has been carried out allowed to establish the frequency of PKU in Poland as $1: 7,500$, frequency of galactosemia as $1: 32,000$, and the frequency of sulfur aminoacid disturbances as lower than $1: 211,000$. Out of the tests being used the highest effectives of Guthrie test is stressed.

88. Multiple screening for inborn errors of metabolism in New Zealand and other countries in the Pacific Basin. A. M. O. VeALE, I. C. T. Lyon, and I. B. Houston. Human Genetics Research Unit, Medical School, Dunedin, New Zealand.

All New Zealand babies have been screened for PKU by the Guthrie method since Ist April 1966. Beginning on 1st January 1969, the testing was transferred to this Unit and the program expanded to include additional tests. All babies were tested by inhibition assay for increased levels of phenylalanine, methionine, leucine, tyrosine, and histidine. Bacterial auxotroph tests for red blood cell enzyme deficiencies in orotic aciduria and argininosuccinic aciduria were also done for a period but have now been stopped. Most N.Z. babies are Europeans (90\%); the balance being almost entirely Polynesians. Additional Polynesian babies as well as Micronesians, Melanesians, and Indians are represented by specimens received from Fiji, New Guinea, the Solomon Islands, Western Samoa, American Samoa, Guam, Niue, Saipan, Yap, and Majuro. Three enzyme tests to detect cases of galactosaemia, hereditary angio-oedema and $\alpha$-1-antitrypsin inhibitor deficiency are also a part of the programme but specimens from outside N.Z. are not suitable for these tests. No definite cases of metabolic errors have been found in specimens received from outside N.Z. but the numbers received are not sufficient to conclude that there is any definite difference in incidence between the various racial groups. In 3.5 years, a total of 215,865 N.Z. babies have been tested. The incidence of PKU is 1:14,391, homocystinuria $1: 107,932$, histidinaemia $1: 10,710$, galactosaemia $1: 32,791$. In non-newborns tested, 1 case of intermittent maple syrup urine disease, 3 of argininosuccinic aciduria, and 15 of hereditary angiooedema have been detected. 
89. Austria newborn screening program for inborn errors of metabolism. O. ThalHaMmer. University Kinderklinik, Wien, Vienna, Austria.

\begin{tabular}{|c|c|c|c|c|}
\hline \multicolumn{5}{|c|}{ Results up to December 31,1971} \\
\hline Anomaly & $\begin{array}{c}\text { No. } \\
\text { newborns }\end{array}$ & No. detected & & Remarks \\
\hline \multirow[t]{2}{*}{ Phenylalaninemia } & 413,464 & PKU & 36 & $1: 11,400$ \\
\hline & & Hyperphen. & 16 & $1: 25,800$ \\
\hline \multirow[t]{2}{*}{ Galaktnsemia } & 412,047 & Transferase & 15 & $1: 27,000$ \\
\hline & & Kinase & 1 & \\
\hline Maple syrup U.D. & 396,050 & & 1 & +1 select \\
\hline Homocystinuria & 320,650 & & 1 & \\
\hline \multirow[t]{2}{*}{ Histidinemia } & 236,762 & & $?$ & total test \\
\hline & 212,000 & & 12 & $\begin{array}{l}\text { completed } \\
\text { follow up } \\
(1: 17,600)\end{array}$ \\
\hline Tyrosinosis & 153,387 & & 0 & \\
\hline $\begin{array}{l}\text { TLG (proline, gly- } \\
\text { cine) }\end{array}$ & 72,000 & & 0 & \\
\hline Total & & & 82 & \\
\hline
\end{tabular}

Beginning March 1966 in Vienna with PKU only, the program expanded gradually into eight of the nine Austrian provinces (except Tyrol) and rapidly into 10 metabolic disturbances. Beside proline and glycine (TLC) variations of Guthrie's bacterial inhibition assay were used. Thin layer chromatography (TLC) was adapted for mass screening (glass strip plates), can employ filter paper blood spots and needs little additional work. TLC is not a substitute of Guthrie's test. Screening is not obligatory in Austria but since $196980 \%$ and in $197188.2 \%$ of all newborns in the eight cooperative provinces were tested.

90. Subtyping of Type III glycogenosis in Israeli patients. S. W. Moses, N. Bashan, G. Agam, and A. Gutman. Pediatrics Research Laboratories, Negev Central Hospital, Beer Sheva and Department of Biochemistry, Hebrew University, Hadassah Medical School, Jerusalem, Israel.

Out of 30 patients with Type III glycogen storage disease (G.S.D. III) described in Israel, 24 were of North African origin. Diagnosis was based on negative glucose response to glucagon administration and absence of amyloglucosidase activity in red and white blood cells, (glucose- $U-{ }^{14} \mathrm{C}$ incorporation method). In most cases the diagnosis was confirmed by assay of enzyme activity in liver and muscle.

The transferase activity of amyloglucosidase and hydrolysis of a glucosyl-Schardinger-dextrin in leucocytes from 10 patients of North African origin were 0.8-3.8 units (\% covering/10 $70^{7}$ cells/ $\mathrm{min})$ and $0.8-2.6$ units $\left(\mu \mathrm{mole} / 10^{7}\right.$ cells $\left./ \mathrm{min}\right)$ respectively. The corresponding values in 14 healthy volunteers were $0.4-3.5$ and 0.8-4.4 units, respectively. Transferase was also measured in four patients of Middle Eastern origin, but no activity was detectable. In selected cases the leucocyte hydrolytic and transferring activity was compared with activities found in muscle and liver.

In contrast to the Mediterranean cases, the North African patients showed a remarkable uniform picture, which was characterised by the unexpected finding of a normal transferase and hydrolase activity when measured separately, whereas no overall amylo-1,6-glucosidase activity (determined by the method of glucose-U. $-{ }^{14} \mathrm{C}$ incorporation into glycogen) was measurable in leucocytes. This unexpected finding suggests that a specific mutation was responsible for the North African cases of G.S.D. III. In addition these findings lead to the conclusion that besides the hydrolytic and transferring properties of amylo-1,6-glucosidase an additional factor is involved affecting over-all enzyme activity as measured by the method of glucose- $\mathrm{U}-\mathrm{C}^{14}$ incorporation into glycogen.

91. An unusual case of glycogenosis of the liver with reduced activity of glucose 6-phosphatase and ultrastructural alterations of the rough endoplasmic reticulum. J. Schaub, A. Paulini, E. Kohne, E. Leupold, and H. J. Bremer. Departments of Pediatrics, University of Munich and Ulm, West Germany.

A case is presented with increased glycogen content of the liver $(17 \%)$ and reduced activity of Glucose-6-Phosphatase of 1,5 $\mu$ moles $/ \mathrm{g} / \mathrm{min}$ (normal:2-10 $\mu$ moles $/ \mathrm{g} / \mathrm{min}$ ). The clinical symptoms are to a certain extent those of Type $\mathbf{I}$ glycogenosis.

Kinetics of the residual enzyme activity are presented. There was found in hepatocytes an uncommon type of "vesiculation" of the rough endoplasmic reticulum, as first described by Spycher and Gitzelmann (Virchows Arch. Abt. B Zellpath., 8: 133 (1971).

The model of Paigen is discussed and implies that the cell membranes are the primary target of a mutation and that enzymes associated with it are altered.

It is considered that the present case is a variant of Type I glycogenosis.

92. Application of new techniques for the identification of chromosomes to diagnostic problems. G. R. Burgio, M. Fraccaro, F. Severi, and L. Tiepolo. Paediatric Clinic and Euratom Unit for Human Radiation and Cytogenetics, University of Pavia, Pavia, Italy.

Application of the fluorescence technique with quinacrine mustard and of Arrighi and Hsu method for constitutive heterochromatin to different problems of chromosome identification are reported. These techniques were applied to $2 \mathrm{XY} / \mathrm{XO}$ Turner syndromes, in order to confirm the presence of a $\mathrm{Y}$ chromosome, to an XO male and to an XX hermaphrodite, in order to identify a possible translocated Y. A Y chromosome was found only in one of the two XY/XO. It may be concluded therefore that in some cases the diagnostic problems may be easily solved, while in others the impossibility to demonstrate $\mathrm{Y}$ material opens more general problems. In two other cases the new techniques revealed karyotypes completely different from those expected. In fact, we identified an XYY karyotype in an infant with clinical symptoms of Patau syndrome, previously interpreted as partial D trisomy, and a 2/12 translocation in a Turner phenotype which had been interpreted as an $\mathrm{X} /$ autosome translocation. Finally, in two cases, (a 13/15 tandem translocation and a $15 / 15$ centric fusion) we could definitely identify the translocated chromosomes. These results suggest the need of a widespread application of these new techniques to chromosomal analysis.

93. Metabolic responses of children to fast, and to subsequent alanine infusion and glucagon test. S. LEISTI and J. Perheentupa. University Children's Hospital, Helsinki, Finland.

Forty children, 3-17 years of age, normal or with prenatal growth disturbance or idiopathic hypoglycaemia, had an alanine infusion (6.5 mmoles $/ \mathrm{kg}$ in $90 \mathrm{~min}$ ) and glucagon test after a 21hr fast. Blood levels of glucose, lactate, acetone bodies, FFA, glycerol, TG, pH, cortisol, insulin, and growth hormone, and the excretion of urea were followed.

Fasting blood glucose concentration showed a large variation with frequent hypoglycaemic levels even in children with no history of hypoglycaemic symptoms. Young children had a 
marked rise of plasma FFA and glycerol levels, associated with ketoacidosis. Fasting plasma insulin concentration was very low in all, and no rise in $\mathbf{G H}$ levels was observed.

The alanine infusion brought about a correction of low blood glucose levels and ketosis. Two patients with a history of spontaneous hypoglycaemia were exceptions. Probably, deficient glyconeogenesis was the cause of their hypoglycaemic disorder. As a rule, alanine induced a rise in plasma insulin and growth hormone levels.

Glucagon regularly caused a distinct rise in blood glucose concentration even during marked hypoglycaemia.

94. Possibility of recovering renal functions postoperatively in malformative uropathies of children. H. MathreU, M. F. Gagnadoux, M. F. Chedru, and M. Boureau. Hôpital Bretonneau, Paris, France.

Renal functions were studied pre- and postoperatively in 22 cases of obstructive uropathies, in order to evaluate the type of postoperative renal improvement. Renal functions were assessed for each kidney, separately, in 10 cases. During the obstruction, the first function to be impaired is the urinary maximal concentrating ability. This impairment is always greater than would imply a nephronic reduction. So, a diabetes insipidus can be observed. The impairment of the urinary maximal concentrating ability can be observed even though GFR is normal. The correlation between GFR and [C] is $y=009 x+1005,4(r=0.737$; $y<0.01)$. An impaired response to an acid load of distal type can also be observed. So, during the obstruction, renal impairment predominates on tubular functions. Post operatively, tubular functions can recover completely, in spite of no change of GFR. Renal impairment is of the type observed in nephronic reduction, and is fixed at a level determined by the number of remaining nephrons. This level can be ascertained by the determination of GFR and of renal mercury fixation three months postoperatively, when there is no longer any functional impairment. Renal function can still improve progressively afterwards, which can be interpreted as a compensatory hypertrophy. As a conclusion, the renal impairment observed during the obstructive phase is inhomogenous. Postoperatively, if the operation is a success, renal functions become homogenous, GFR and tubular functions being impaired in the same way. If renal impairment remains inhomogenous, it means that the operative procedure was not a success.

95. Severe choreic-ataxic syndrome treated by L-DOPA (report of two cases). M. Gregoriou and N. MATSANiorrs. Athens Uni- versity, Department of Pediatrics, "St. Sophie's" Children's Hospital, Goudi, Athens, Greece.

The well established treatment of Parkinsonism with L-DOPA encouraged us to try this drug in two children, aged 11 and 12 years respectively, suffering from an incapacitating choreic-ataxic syndrome. Such cases were first described by Malmud and Cohen in 1958 and these two children fitted well in this category. They were put on increasing daily doses of L-DOPA (up to $2-5 \mathrm{~g}$ ) within 1 month.

The results were surprisingly beneficial. Both choreic movements and ataxia almost disappeared. These results persisted for the 10-month follow-up period during which the patients continued to receive $2.5-3 \mathrm{~g}$ of L-DOPA daily.

96. Validity of Lyon's hypothesis in X-linked human myopathies. M. Hans. Department of Pediatrics, University of Berne, Inselspital, Berne, Switzerland.

Serum creatine kinase activity (CK) was measured in 20 known and 44 possible carriers (50\% genetic risk) of Duchenne muscular dystrophy. $80 \%$ of the known carriers, $60 \%$ of the possible carriers aged below 20 years had elevated $\mathrm{CK}$ activities. This suggests that carrier detection rate might be higher in younger girls than in adult females. Muscle biopsies were performed in two known and six possible carriers having elevated $\mathrm{CK}$ activity and/or myopathic symptoms. In seven out of the eight cases myopathic changes were found histologically. No significant correlation was found between CK activity in serum and grade of histopathological alterations. However, histology may also facilitate the diagnosis of heterozygosity. Myopathic symptoms were observed clinically in three known and 3 possible carriers; two of them were only mildly affected but four carriers were severely handicaped, two being no longer able to walk. CK activities in those two cases were normal, suggesting atrophy of all muscle fibers affected. "Lyonization" alone cannot explain the wide biochemical, histological and clinical variability of gene expression in heterozygotes. Since inactivation of the $\mathrm{X}$ chromosome takes place between the 12th and 16th day of gestation a 50:50\% distribution of normal and myopathic muscle fibers should be expected in more than $90 \%$ of carriers. The fact that about $20 \%$ of the carriers escape detection by our criteria and that sometimes accumulation of both types of those borderline cases is observed within one and the same family, prompts speculation on a possible genetic influence of $\mathrm{X}$ chromosome inactivation: three carriers with myopathic symptoms (mother and two daughters) and three out of the four genetically proven carriers with normal CK (two sisters and one cousin). 